\title{
Bilateral Alterations in Local Cerebral Glucose Utilization Following Intranigral Application of the GABAergic Agonist Muscimol
}

\author{
Catherine R. Dermon, Patricia Pizarro, Philip Georgopoulos, and Helen E. Savaki \\ Laboratory of Physiology, Department of Basic Sciences, Division of Medicine, School of Health Sciences, University of \\ Crete, 71409 Iraklion, Crete, Greece
}

\begin{abstract}
Rates of cerebral glucose utilization were measured by means of the autoradiographic 2-deoxy-D- $\left[1-{ }^{14} \mathrm{C}\right]$ glucose technique in $\mathbf{7 0}$ anatomically discrete central nervous structures in conscious awake rats following unilateral intranigral application of the GABAergic agonist muscimol. Intranigral injection of $1.3 \mu \mathrm{l} 1 \mu \mathrm{M}$ muscimol $(0.15 \mathrm{ng})$ induced increases in glucose consumption locally in the substantia nigra reticulata (by $87 \%$ ), distally in the contralateral reticulata, red nucleus, nucleus accumbens, and prefrontal cortex, and bilaterally in the pyriform cortex, as compared to values in control animals. Intranigral injection of $1.3 \mu \mathrm{l} 1 \mathrm{~mm}$ muscimol (150 $\mathrm{ng}$ ) effected a local metabolic activation in the substantia nigra reticulata (by $111 \%$ compared to the control group) and in compacta (by $18 \%$ ), as well as a distal activation in the contralateral reticulata (by $39 \%$ ) and contralateral compacta (by $29 \%$ ). Beyond the structures affected by the lower dose, the higher dose of muscimol elicited widespread bilateral increases in glucose metabolism in the rat brain. Among the principal nigral reticulata efferent projections, the deep superior colliculi displayed ipsilateral metabolic activation (by $30 \%$ ), whereas the parafascicular, mediodorsal, and ventromedial thalamic projecting areas, as well as the pedunculopontine nucleus, displayed bilateral activations compared to the control animals. The ventromedial and ventrolateral thalamic nuclei contralateral to the injected substantia nigra reticulata were $20 \%$ activated compared to the ipsilateral homologous structures and $30 \%$ activated compared to the control rats. The areas that send afferent projections to the reticulata (globus pallidus, entopeduncular and subthalamic nuclei) were mainly activated contralateral to the injected reticulata compared to values for control animals. In general, following intranigral muscimol ( $1 \mathrm{~mm}$ ) injection, glucose metabolism was activated to a larger extent on the side contralateral to the injection than on the ipsilateral side.

It is suggested that the present findings are due to a presynaptic nigral effect of muscimol on the GABAergic autoreceptors of the striatonigral terminals and to a consequent disinhibition of the reticulata GABAergic output.
\end{abstract}

\footnotetext{
Received Dec. 18, 1989; revised Mar. 19, 1990; accepted Mar. 26, 1990.

This work was supported by Grant $86 \Gamma 856$ from the Greek Ministry of IndustryEnergy-Technology, General Secretariat of Research and Technology. We wish to thank Pr. J. Glowinski, Pr. M. J. Besson, and Dr. M. Desban for their support. We also thank Dr. M. Tzagournissakis and Mr. V. Raos for their technical assistance.

Correspondence should be addressed to Dr. Helen Savaki, Laboratory of Physiology, Department of Basic Sciences, Division of Medicine, University of Crete, Greece.

Copyright (C) 1990 Society for Neuroscience $0270-6474 / 90 / 092861-18 \$ 03.00 / 0$
}

There is considerable literature concerning basal ganglia functioning, suggesting overall a basal ganglia role in gating sensory inputs into other motor areas and in attention and cognition (Lidsky et al., 1985). In our previous studies, we attempted to define the functional pathways associated with one of the main output components of the basal ganglia, the substantia nigra (SN).

The effects of unilateral electrical stimulation of the SN were examined to gain insight concerning (1) the poorly understood relationships between the basal ganglia and the major motor systems of the cerebellum and cortex, and (2) the growing evidence concerning reciprocal regulations of the nigrostriatal dopaminergic (DAergic) pathway (Chéramy et al., 1981) and the striatonigral GABAergic system (Gauchy et al., 1980), in spite of the lack of direct interhemispheric connections. Unilateral SN reticulata (SNR) stimulation elicited metabolic activations in several bilateral extrapyramidal structures in awake rats and only few unilateral (ipsilateral to the stimulated nigra) activations in halothane-anesthetized animals (Savaki et al., 1983b). This finding, that halothane-anesthesia masks the effects induced by $\mathrm{SN}$ stimulation in a few specific brain regions anatomically associated with the nigra, indicates that the anesthetic agent is a possible source of the contradictory neurophysiological observations reported in the literature (Bunney et al., 1973; Bunney and Aghajanian, 1976; McCulloch et al., 1979; Wechsler et al., 1979). Furthermore, because no major direct anatomical connections had been described between the basal ganglia of the 2 hemispheres (Gerfen et al., 1982), and because halothane itself markedly decreased the glucose use within the thalamus and cortex specifically (Savaki et al., 1983a), we proposed at that stage that the halothane-induced depression of polysynaptic pathways, mediated via thalamocortical relays, could be responsible for the masking effects of anesthesia (Savaki et al., 1983b).

In our attempt to investigate further the possible interthalamic transfer of information from one SNR to the contralateral basal ganglia components, we lesioned the major connection to the thalamus, the ventromedial thalamic nucleus (VM). The metabolic depressions induced by unilateral VM lesion occurred through anterograde pathways 1 week after the lesion and had not recovered after 1 month, whereas retrograde degeneration made only a minor contribution (Girault et al., 1985). However, unilateral lesion of the VM projection field of the SNR prior to ipsilateral SNR stimulation induced reversible reticulata hypoexcitability and a lack of responsiveness in areas receiving reticulata efferents. It was then suggested that distal axonal injury (in the VM) induced reversible retrograde reactions in the nigral parent cells (in the SNR) and their uninjured collaterals 
(Savaki et al., 1984a). The regional cerebral metabolic effects induced by unilateral SNR stimulation 8 and $30 \mathrm{~d}$ following ipsilateral VM lesions demonstrated that (1) the stimulation of the SNR polysynaptically activates several neuronal systems bilaterally and in parallel; (2) the role of the VM in mediating most of these activations is central; and (3) the plasticity of the adult CNS allows for recovery of metabolic responsiveness ( $\mathrm{Sa}$ vaki et al., 1984b, 1985).

Nevertheless, electrical stimulation of the SNR may cause (1) orthodromic excitation in projecting areas via direct DAergic and GABAergic (monosynaptic) or indirect (polysynaptic) nigrofugal neurons, (2) antidromic activation of nigral afferent fibers, and (3) activation of fibers passing through the SNR. In order to further define some of the above-mentioned effects of SNR stimulation by isolating nigral pathways based on their use of different neurotransmitters, we manipulated the GABAergic nigral system specifically by locally injecting the agonist muscimol. It has been postulated that there are 2 distinct but functionally linked pools of GABA within the SNR. The larger one ( $90 \%$ of total) resides in the axon terminals of slowly firing striatonigral fibers and has a low turnover, whereas the smaller one $(10 \%)$ is present in the perikarya and collaterals of rapidly firing neurons and has a high turnover rate (Starr et al., 1983). Intranigrally applied muscimol may act locally via presynaptic GABA autoreceptors of striatonigral terminals to disinhibit reticulata cells (Arbilla et al., 1979), or it may act via postsynaptic receptors on nigral cells to increase their tonic inhibition (Waszczak et al., 1980).

In conclusion, the present experiments were undertaken to define further specific functional associations of the SNR in the rat brain using the quantitative autoradiographic technique of ${ }^{14} \mathrm{C}$-deoxyglucose (Sokoloff et al., 1977) in combination with the pharmacological manipulation of the reticulata GABAergic system by intranigral application of muscimol. Part of this work has appeared in abstract form (Dermon et al., 1989).

\section{Materials and Methods}

Male Sprague-Dawley rats weighing 350-400 gm (Charles Rivers) were allowed free access to food and water prior to surgical preparation. Polyethylene catheters were inserted into 1 femoral artery and vein, and an injector (external diameter, $0.3 \mathrm{~mm}$ ) was implanted stereotaxically into the right SNR under light halothane anesthesia (halothane/nitrous oxide/oxygen $1 \%: 67: 33 \mathrm{v} / \mathrm{v}$ ). The experimentally determined coordinates for the SNR were $A=2.8-3, \mathrm{~L}=1.8-2.2$, and $\mathrm{H}=2.0-2.2$. The injector was sealed on the skull using dental cement, and the animal, encased in a loose-fitting plaster cast around the lower abdomen, was allowed to recover from anesthesia for an average of $3 \mathrm{hr}$.

Five minutes before the intravenous ${ }^{14} \mathrm{C}$-deoxyglucose $\left({ }^{14} \mathrm{C}\right.$-DG) injection $(100 \mu \mathrm{Ci} / \mathrm{kg}$; specific activity, $5 \mathrm{mCi} / \mathrm{mmol}$; New England $\mathrm{Nu}$ clear) the intranigral injection of saline (group of 8 control rats), $1 \mu \mathrm{M}$ muscimol (group of 7 rats), and $1 \mathrm{~mm}$ muscimol (group of 6 rats) was started by means of a microsyringe attached to a Harvard pump. The intranigral injection continued for $10 \mathrm{~min}$ following the ${ }^{14} \mathrm{C}$-DG administration (total vol, $1.3 \mu \mathrm{l}$ injected within $15 \mathrm{~min}$ ). Consequently, the total dose of muscimol injected into the SNR of each rat was $0.15 \mathrm{ng}$ in the group of 7 rats and $150 \mathrm{ng}$ in the group of 6 rats. The position of the tip of the injector was confirmed by histological examination, the size of the injectate was visualized by the use of Evans blue $(0.1 \%)$ in the injected solution, and the exact size of the activated area within the right SNR following muscimol injection was determined in serial sections on the autoradiograms. Blood pressure, heart rate, body temperature, and blood ${ }_{p} \mathrm{O}_{2},{ }_{p} \mathrm{CO}_{2}$, and $\mathrm{pH}$ were always estimated to be within the normal range before the administration of ${ }^{14} \mathrm{C}-\mathrm{DG}$. Arterial blood samples were obtained during the succeeding $45 \mathrm{~min}$, and the glucose and ${ }^{14} \mathrm{C}$-DG plasma concentrations were measured as required (Sokoloff et al., 1977).
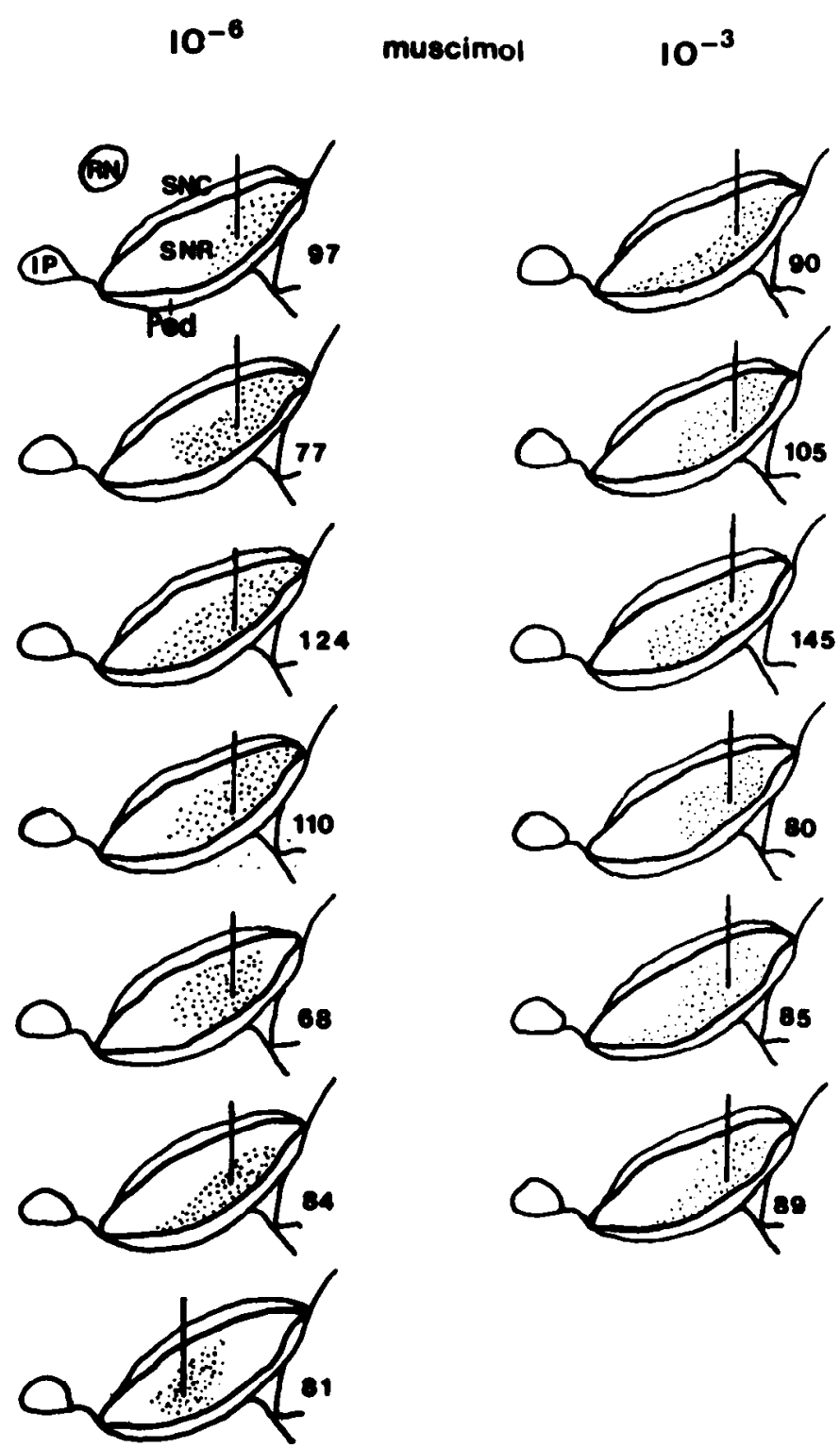

Figure 1. Diagrammatic representation of the extension of the nigral subregion, displaying increased glucose metabolism following muscimol injection. The diagrams are based on the autoradiographic sections with the maximal extension of metabolic activation in each case. The dotted area represents the intranigral area that displayed markedly increased optical density following muscimol injection. The vertical line within each dotted area represents the exact localization of the injector tip. The values next to each diagram correspond to the local glucose utilization within the metabolically activated area, expressed in $\mu \mathrm{mol} / 100 \mathrm{gm}$ of tissue/min. Brain structures according to the Appendix.

Forty-five minutes after the ${ }^{14} \mathrm{C}-\mathrm{DG}$ administration, the rats were decapitated, and the brains were removed and frozen in isopentane cooled to $-40^{\circ} \mathrm{C}$. Coronal brain sections of $20 \mu \mathrm{m}$ thickness were obtained on a cryostat microtome at $-20^{\circ} \mathrm{C}$ and thaw-mounted onto slides. The slides were exposed to Kodak OM-1 X ray films in X-ray cassettes that were stored in a dark, cool environment for approximately $20 \mathrm{~d}$. These autoradiograms were then matched with corresponding stained sections for the exact localization of the intranigral subregion activated by muscimol.

The effect of intranigral muscimol injection on local cerebral glucose utilization was examined in 70 rat brain regions named according to the Paxinos atlas (Paxinos and Watson, 1982). Local cerebral tissue concentrations of ${ }^{14} \mathrm{C}$ were determined by quantitative densitometry using a computer-assisted densitometer (Quantimet 970, Cambridge 
Table 1. Bilateral effects of muscimol injection in the right substantia nigra on local cerebral glucose utilization in brainstem and cerebellum

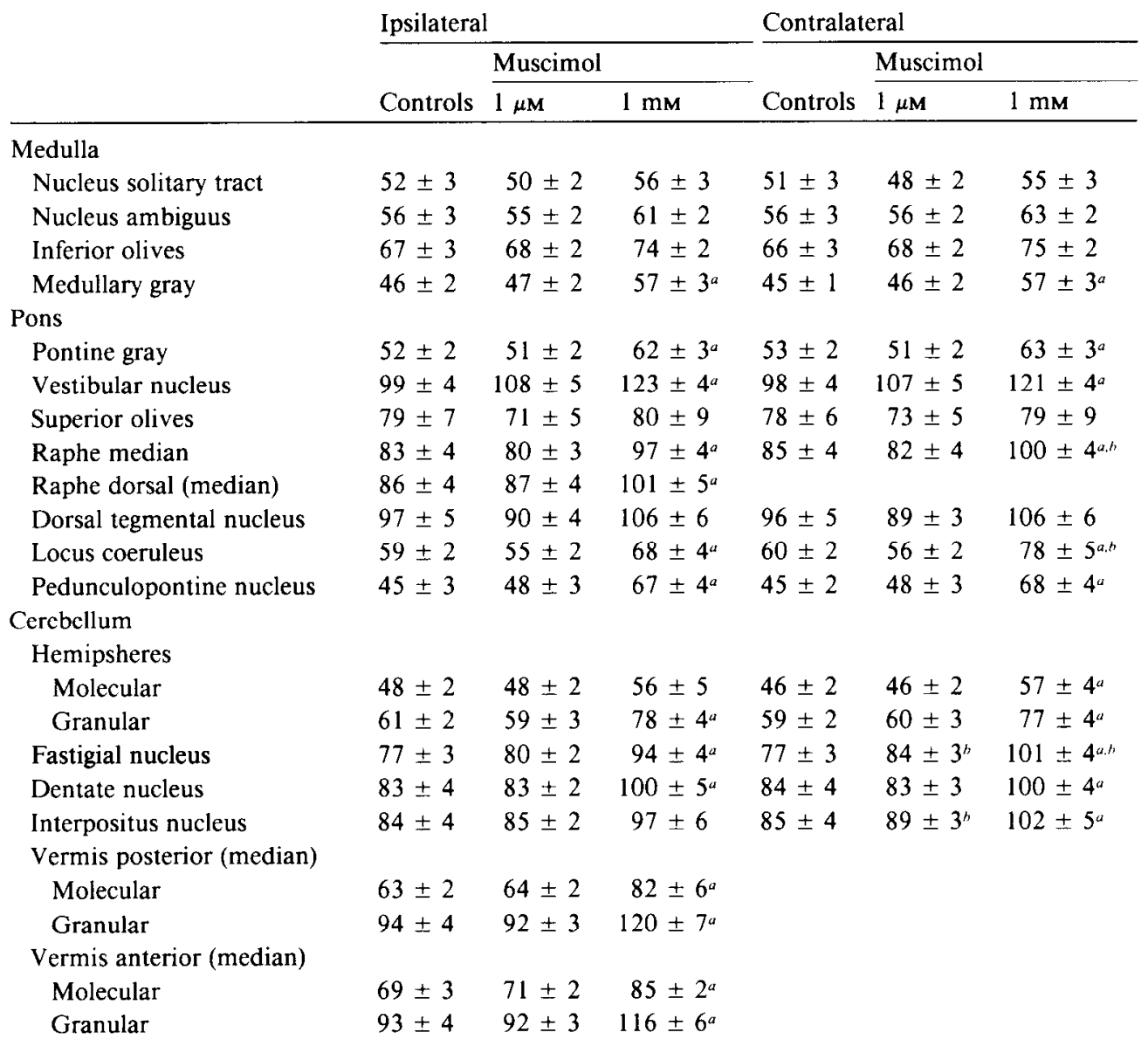

Values represent the mean $\pm \mathrm{SEM}$ of glucose utilization expressed in $\mu \mathrm{mol} / 100 \mathrm{gm} / \mathrm{min}$, obtained in 8 awake control rats, 7 rats injected intranigrally with $1 \mu \mathrm{M}$ muscimol, and 6 rats injected intranigrally with $1 \mathrm{~mm}$ muscimol.

a Significances at $p<0.05$ level, estimated by one-way analysis of variance followed by Student's $t$-test.

${ }^{b}$ Side-to-side significant differences at the $p<0.05$ level, calculated by the paired $t$-test.

Instruments). Seven precalibrated ${ }^{14} \mathrm{C}$ standards exposed together with the brain sections were used as reference. Six ipsilateral and 6 contralateral (to the injected nigra) determinations of optical density were made for each brain area investigated in each animal.

Using Sokoloff's original equation (Sokoloff et al., 1977), the glucose consumption in discrete brain areas was calculated from the measured concentrations of ${ }^{14} \mathrm{C}$ and glucose in arterial plasma samples during the experimental period, from brain tissue concentrations of ${ }^{14} \mathrm{C}$ determined hy the densitometric analysis, and from the appropriate constants for the rat.

The data were analyzed for statistical significances by 1 -way analysis of variance (ANOVA test). Whenever a statistically significant interaction was found (with the ANOVA test), the data were further analyzed by the unpaired 2-tailed Student's $t$-test applied between the salineinjected group of animals and the $1 \mathrm{~mm}$ or $1 \mu \mathrm{M}$ muscimol-injected group. Ipsilateral-to-contralateral differences were estimated within each of the 3 groups using the paired $t$-test.

\section{Results}

In all the rats subjected to intranigral injection of muscimol ( 1 $\mu \mathbf{M}$ or $1 \mathrm{mM}$ ), the autoradiograms always demonstrated a welllimited area of markedly increased optical density all around the tip of the injector and only within the $\mathrm{SN}$.

Figure 1 represents the extension of the intranigral area displaying increased glucose use following muscimol injection in all injected rats of both the low- and high-dose groups. These diagrams are based on magnification of autoradiographic scctions at the anteroposterior level of the maximal extension of the metabolically activated area.

The behavioral response of rats to intranigral injection of the $1 \mu \mathrm{M}$ muscimol dose was characterized by shivering, piloerection, spontaneous movements of the head, and intermittent sniffing and exploring. Contralateral turning of the head was observed in 1 rat, ipsilateral turning of the head in 3 rats, and no turning in the other 3 rats. The response of the rats to the injection of the $1 \mathrm{~mm}$ dose of muscimol was characterized by hyperactivity, spontaneous movements of the head, and intermittent sniffing, exploring, and gnawing. The higher dose of muscimol induced contralateral turning of the upper part of the body in 5 rats and ipsilateral turning in 1 rat.

\section{Cerebral metabolic effects caused by intranigral injection of 1 $\mu \mathrm{M}$ muscimol}

The effects induced by unilateral intranigral application of muscimol $(1 \mu \mathrm{M})$ on glucose consumption within ipsilateral and contralateral structures were analyzed as indicated in Materials and Methods. Glucose utilization was locally enhanced by $87 \%$ in the injected right SNR. Energy metabolism was also significantly increased (12\%) in the contralateral SNR. Among the 70 
Table 2. Bilateral effects of muscimol injection in the right substantia nigra on local cerebral glucose utilization in mesencephalon and white matter

\begin{tabular}{|c|c|c|c|c|c|c|}
\hline & \multicolumn{3}{|c|}{ Ipsilateral } & \multicolumn{3}{|c|}{ Contralateral } \\
\hline & \multirow[b]{2}{*}{ Controls } & \multicolumn{2}{|l|}{ Muscimol } & \multirow[b]{2}{*}{ Controls } & \multicolumn{2}{|c|}{ Muscimol } \\
\hline & & $1 \mu \mathrm{M}$ & $1 \mathrm{~mm}$ & & $1 \mu \mathrm{M}$ & $1 \mathrm{~mm}$ \\
\hline \multicolumn{7}{|l|}{ Mesencephalon } \\
\hline Substantia nigra compacta & $57 \pm 3$ & $63 \pm 4$ & $67 \pm 4^{a}$ & $58 \pm 3$ & $62 \pm 3$ & $75 \pm 4^{a, n}$ \\
\hline Substantia nigra reticulata & $47 \pm 2$ & $88 \pm 9^{a . h}$ & $99 \pm 9^{a . b}$ & $49 \pm 2$ & $55 \pm 3^{a}$ & $68 \pm 3^{a}$ \\
\hline Ventral tegmental area & $42 \pm 2$ & $45 \pm 3$ & $51 \pm 3$ & $42 \pm 2$ & $44 \pm 3$ & $51 \pm 3$ \\
\hline $\begin{array}{l}\text { Oculomotor complex } \\
\text { (Edinger-Westphal }+\end{array}$ & & & & & & \\
\hline III rd nucleus) & $81 \pm 4$ & $84 \pm 4$ & $108 \pm 7^{a}$ & $82 \pm 4$ & $85 \pm 4$ & $110 \pm 6^{a}$ \\
\hline Red nucleus & $66 \pm 3$ & $73 \pm 3$ & $78 \pm 3^{a}$ & $67 \pm 3$ & $74 \pm 3^{a}$ & $83 \pm 3^{a, h}$ \\
\hline $\begin{array}{l}\text { Interpeduncular nucleus } \\
\text { (median) }\end{array}$ & $91 \pm 5$ & $101 \pm 4$ & $118 \pm 7^{a}$ & & & \\
\hline \multicolumn{7}{|l|}{ Superior colliculi } \\
\hline Superficial layer & $78 \pm 4$ & $83 \pm 5$ & $92 \pm 3$ & $81 \pm 4$ & $84 \pm 5$ & $94 \pm 2$ \\
\hline Deep layer & $75+3$ & $83+4^{b}$ & $97+3^{a, b}$ & $78+3$ & $79 \pm 4$ & $84 \pm 2$ \\
\hline \multicolumn{7}{|l|}{ White Matter } \\
\hline Cerebellar white & $28 \pm 1$ & $26 \pm 1$ & $30 \pm 2$ & $27 \pm 1$ & $27 \pm 1$ & $30 \pm 2$ \\
\hline Internal capsule & $23 \pm 1$ & $25 \pm 2$ & $27 \pm 2$ & $23 \pm 1$ & $25 \pm 2$ & $27 \pm 2$ \\
\hline Corpus callosum & $24 \pm 1$ & $26 \pm 2$ & $28 \pm 2$ & $24 \pm 1$ & $26 \pm 2$ & $28 \pm 2$ \\
\hline
\end{tabular}

Values represent the mean \pm SEM of glucose utilization expressed in $\mu \mathrm{mol} / 100 \mathrm{gm} / \mathrm{min}$, obtained in 8 awake control rats, 7 rats injected intranigrally with $1 \mu \mathrm{M}$ muscimol, and 6 rats injected intranigrally with $1 \mathrm{~mm}$ muscimol.

"Significances at $p<0.05$ level, estimated by one-way analysis of variance followed by Student's $t$-test.

${ }^{b}$ Side-to-side significant differences at the $p<0.05$ level, calculated by the paired $t$-test.

anatomically discrete structures examined, only 5 brain regions (including the SNR) were affected by intranigral injection of the low dose of muscimol when the data were analyzed by 1-way ANOVA followed by Student's $t$-test. The affected brain areas (all of them displaying increased glucose use compared to the controls) were the red nucleus contralateral to the injected SNR ( $10 \%$ increase), the contralateral nucleus accumbens $(14 \%$ increase), the contralateral prefrontal cortex ( $22 \%$ increase), and the pyriform cortex (bilateral increase: $16 \%$, contralateral; $14 \%$, ipsilateral). However, $t$-paired statistical analysis revealed ipsilateral-to-contralateral (to the injected SNR) differences in several brain regions following intranigral injection of $1 \mu \mathrm{M}$ muscimol. Among the deep cerebellar nuclei, the fastigeal and intcrpositus nuclei displayed significantly higher metabolic activity on the contralateral side compared to the ipsilateral side (Table 1). In the mesencephalon, the SNR and the deep layer of the superior colliculi displayed significantly higher activity on the ipsilateral side than on the contralateral side (Table 2). In the diencephalon, the medial habenula and the parafascicular and anteromedial thalamic nuclei demonstrated higher metabolic activity on the ipsilateral side compared to the contralateral homologous nuclei. However, the rest of the affected thalamic nuclei (the centrolateral, lateral posterior, ventrobasal, ventromedial, reticularis, and ventrolateral nuclei) displayed a higher activity on the side contralateral to the injected SNR than on the ipsilateral side (Table 3). No side-to-side differences were demonstrated within the rhinencephalon and the basal ganglia. Within the neocortex, the ipsilateral frontal, prefrontal, parietal, sensory, motor, and anterior cingulate cortices displayed significantly lower metabolic activity compared to the contralateral homologous regions (Table 4).

\section{Cerebral metabolic effects induced by intranigral injection of 1 mм muscimol}

The effects induced by unilateral intranigral application of $1 \mathrm{~mm}$ muscimol on glucose utilization in the bilateral brain regions examined were statistically analyzed as indicated in the Materials and Methods section.

Brain stem and cerebellum. The alterations of glucose consumption in various examined regions of the brainstem and cerebellum observed ipsilateral and contralateral to the $1 \mathrm{~mm}$ muscimol-injected SNR are listed in Table 1. Unilateral (right) intranigral injection significantly increased the rates of glucose use in the medullary and pontine gray, the vestibular nucleus, the dorsal and median raphe, the locus coeruleus, the pedunculopontine nucleus, the cerebellar hemispheres, the vermis, and the fastigial, interpositus, and dentate deep cerebellar nuclei (Figs. 2, 3, and 4). All these regions were bilaterally activated (with the exception of the molecular layer in the cerebellar hemispheres and the nucleus interpositus, which were activated only contralaterally) compared to the control and compared to the $1 \mu \mathrm{M}$ muscimol dose values. Only 3 of these areas demonstrated significant side-to-side differences when analyzed by the paired $t$-test. Specifically, the median raphe, the locus coeruleus, and the fastigial nucleus displayed a higher metabolic activity on the side contralateral to the injected SNR than on the ipsilateral side.

Mesencephalon and white matter structures. At the mesencephalic level, the prominent effect was the enhanced metabolic activity (by $111 \%$ compared to the control value) within the injected right SNR (Figs. 1 and 4). Glucose metabolism was also activated in the contralateral SNR (by 39\%). The ipsilateral 
Table 3. Bilateral effects of muscimol injection in the right substantia nigra on local cerebral glucose utilization in diencephalon

\begin{tabular}{|c|c|c|c|c|c|c|}
\hline & \multicolumn{3}{|l|}{ Ipsilateral } & \multicolumn{3}{|c|}{ Contralateral } \\
\hline & \multirow[b]{2}{*}{ Controls } & \multicolumn{2}{|l|}{ Muscimol } & \multirow[b]{2}{*}{ Controls } & \multicolumn{2}{|l|}{ Muscimol } \\
\hline & & $1 \mu \mathrm{M}$ & $1 \mathrm{~mm}$ & & $1 \mu \mathrm{M}$ & $1 \mathrm{~mm}$ \\
\hline Lateral geniculate body & $68 \pm 4$ & $70 \pm 4$ & $74 \pm 6$ & $68 \pm 4$ & $72 \pm 4$ & $75 \pm 5$ \\
\hline \multicolumn{7}{|l|}{ Habenula } \\
\hline Lateral & $99 \pm 5$ & $101 \pm 4$ & $120 \pm 5^{a}$ & $102 \pm 5$ & $105 \pm 3$ & $120 \pm 4^{a}$ \\
\hline Medial & $70 \pm 3$ & $72 \pm 2^{b}$ & $87 \pm 4^{a . b}$ & $69 \pm 3$ & $67 \pm 2$ & $74 \pm 2$ \\
\hline \multicolumn{7}{|l|}{ Thalamic nuclei } \\
\hline Parafascicular & $75 \pm 2$ & $78 \pm 3^{h}$ & $94 \pm 6^{a}$ & $75 \pm 2$ & $74 \pm 3$ & $93 \perp 5^{a}$ \\
\hline Mediodorsal & $96 \pm 5$ & $99 \pm 4$ & $118 \pm 8^{a}$ & $96 \pm 5$ & $99 \pm 4$ & $120 \pm 7^{a}$ \\
\hline Centrolateral & $82+3$ & $78+3$ & $82+5$ & $83 \pm 3$ & $81 \pm 4^{b}$ & $92 \pm 6^{b}$ \\
\hline Centromedian (median) & $73 \pm 4$ & $67 \pm 4$ & $73 \pm 4$ & & & \\
\hline Lateral posterior & $88 \pm 5$ & $86 \pm 5$ & $89 \pm 5$ & $88 \pm 5$ & $89 \pm 5^{b}$ & $101 \pm 5^{b}$ \\
\hline Ventrobasal complex & $84 \pm 4$ & $80 \pm 3$ & $98 \pm 4^{a}$ & $85 \pm 4$ & $91 \pm 5^{b}$ & $113 \pm 4^{a, b}$ \\
\hline Ventromedial & $94 \pm 4$ & $90 \pm 3$ & $109 \pm 5^{a}$ & $95 \pm 5$ & $101 \pm 5^{b}$ & $126 \pm 9^{a, b}$ \\
\hline Reticularis & $69 \pm 3$ & $66 \pm 5$ & $71 \pm 3$ & $70 \pm 3$ & $76 \pm 4^{b}$ & $89 \pm 5^{a, b}$ \\
\hline $\begin{array}{l}\text { Intra-anteromedial } \\
\text { (median) }\end{array}$ & & $108 \pm 6$ & $117 \pm 7$ & $127 \pm 6$ & & \\
\hline Anteromedial & $105 \pm 6$ & $108 \pm 3^{b}$ & $126 \pm 8^{a}$ & $103 \pm 5$ & $105 \pm 4$ & $129 \pm 8^{a}$ \\
\hline Anteroventral & $104 \pm 6$ & $103 \pm 4$ & $120 \pm 9$ & $105 \pm 5$ & $103 \pm 3$ & $124 \pm 8^{a . b}$ \\
\hline Ventrolateral & $93 \pm 5$ & $91 \pm 3$ & $100 \pm 8$ & $94 \pm 4$ & $96 \pm 3^{b}$ & $120 \pm 10^{a . b}$ \\
\hline Subthalamic nucleus & $76 \pm 3$ & $77 \pm 3$ & $88 \pm 3^{a}$ & $76 \pm 3$ & $78 \pm 3$ & $99 \pm 6^{a . b}$ \\
\hline $\begin{array}{l}\text { Mamillary complex } \\
\text { (median) }\end{array}$ & $96 \pm 4$ & $105 \pm 6$ & $119 \pm 9$ & & & \\
\hline Hypothalamus (posterior) & $47 \pm 2$ & $49 \pm 2$ & $57 \perp 3$ & $46 \pm 1$ & $50 \pm 2$ & $56 \pm 3$ \\
\hline
\end{tabular}

Values represent the mean $\pm \mathrm{SEM}$ of glucose utilization expressed in $\mu \mathrm{mol} / 100 \mathrm{gm} / \mathrm{min}$, obtained in 8 awake control rats, 7 rats injected intranigrally with $1 \mu \mathrm{M}$ muscimol, and 6 rats injected intranigrally with 1 mM muscimol

" Significances at $p<0.05$ level, estimated by one-way analysis of variance followed by Student's $t$-test.

${ }^{\circ}$ Side-to-side significant differences at the $p<0.05$ level, calculated by the paired $t$-test.

SN-compacta (SNC) was activated by only $18 \%$, whereas the contralateral SNC was activated by $29 \%$.

The oculomotor complex and the red nucleus displayed bilateral metabolic activations following unilateral intranigral 1 mM muscimol injection, whereas the decp layer of the superior colliculi was found to be only ipsilaterally activated. The interpeduncular nucleus was also metabolically activated, whereas no white matter structure displayed any increase in glucose use. Most of the metabolic activations in the mesencephalon were significant between the $1 \mathrm{~mm}$ dose and control groups and between the $1 \mathrm{~mm}$ dose and $1 \mu \mathrm{M}$ dose groups, with the exceptions of the ipsilateral SNR, SNC, and red nucleus, which were activated only in comparison to controls and not in comparison to the $1 \mu \mathrm{M}$ dose group. Statistical analysis using the paired $t$-test revealed that the contralateral $S N C$ and the red nucleus were more activated than the ipsilateral homologous structures, whereas the ipsilateral SNR and the deep layer of the superior colliculi were more activated than the contralateral homologous regions (Table 2 ).

Diencephalic areas. Unilateral intranigral injection of $1 \mathrm{~mm}$ muscimol resulted in markcd clcvations of metabolic activity widely distributed in the rat diencephalon (Figs. 5, 6, 7).

On the ipsilateral side, the structures that displayed increased metabolic rates compared to both control and $1 \mu \mathrm{M}$ dose values were the medial and lateral habenula, and the parafascicular, mediodorsal, ventrobasal, ventromedial, anteromedial, and subthalamic nuclei. On the contralateral side, significantly in- creased metabolic activity, compared to both control and $1 \mu \mathrm{M}$ dose values, was observed in the lateral habenula, parafascicular, mediodorsal, ventrobasal, ventromedial, anteromedial, and subthalamic nuclei, as well as in thalamic nuclei (reticularis, anteroventral, and ventrolateral), that were not affected ipsilaterally. Analysis with the paired $t$-test revealed that the contralateral centrolateral, lateral posterior, ventrobasal, ventromedial, reticularis, anteroventral, ventrolateral thalamic nuclei and the subthalamic nucleus were significantly more activated than the ipsilateral homologous structures. Among those examined, the only thalamic region that demonstrated more activation on the ipsilateral side than on the contralateral side was the medial habenula (Table 3).

Telencephalic regions. Intranigral injection of $1 \mathrm{~mm}$ muscimol induced no metabolic changes in the rhinencephalic regions examined.

Among the basal ganglia, the contralateral globus pallidus and entopeduncular nucleus (Fig. 6) were significantly activated compared to both control and low dose values. Moreover, the nucleus accumbens was bilaterally activated compared to control group values (Fig. 8).

Within the cerebral cortex, significant elevations of glucose consumption were observed contralaterally in the prefrontal cortex and bilaterally in the pyriform cortex, as compared to the respective regions in the control group (Table 4). Although the glucose use values in the contralateral frontal, parietal, sensory, motor, visual, and posterior cingulate cortices were not 
Table 4. Bilateral effects of muscimol injection in the right substantia nigra on local cerebral glucose utilization in telencephalon

\begin{tabular}{|c|c|c|c|c|c|c|}
\hline & \multicolumn{3}{|l|}{ Ipsilateral } & \multicolumn{3}{|c|}{ Contralateral } \\
\hline & \multirow[b]{2}{*}{ Controls } & \multicolumn{2}{|c|}{ Muscimol } & \multirow[b]{2}{*}{ Controls } & \multicolumn{2}{|l|}{ Muscimol } \\
\hline & & $1 \mu \mathrm{M}$ & $1 \mathrm{~mm}$ & & $1 \mu \mathbf{M}$ & $1 \mathrm{mM}$ \\
\hline \multicolumn{7}{|l|}{ Rhinencephalon } \\
\hline Hippocampus & $67 \pm 2$ & $69 \pm 2$ & $72 \pm 3$ & $67 \pm 2$ & $71 \pm 3$ & $74 \pm 2$ \\
\hline Dentate gyrus & $59 \pm 2$ & $58 \pm 2$ & $62 \pm 2$ & $58 \pm 2$ & $57 \pm 3$ & $61 \pm 3$ \\
\hline Amygdala complex & $43 \pm 2$ & $44 \pm 2$ & $47 \pm 3$ & $42 \pm 2$ & $44 \pm 2$ & $46 \pm 3$ \\
\hline Septum (medial part) & $53 \pm 2$ & $60 \pm 4$ & $62 \pm 4$ & $54 \pm 3$ & $61 \pm 4$ & $64 \pm 4$ \\
\hline \multicolumn{7}{|l|}{ Basal ganglia } \\
\hline \multicolumn{7}{|l|}{ Posterior striatum } \\
\hline Dorsolateral part & $87 \pm 4$ & $95 \pm 5$ & $101 \pm 7$ & $89 \pm 4$ & $96 \pm 5$ & $102 \pm 6$ \\
\hline Ventromedial part & $87 \pm 5$ & $92 \pm 4$ & $98 \pm 7$ & $87 \pm 4$ & $94 \pm 4$ & $99 \pm 7$ \\
\hline Anterior striatum (central) & $86 \pm 4$ & $94 \pm 5$ & $100 \pm 4$ & $86 \pm 4$ & $94 \pm 5$ & $101 \pm 4$ \\
\hline Globus pallidus & $50 \pm 3$ & $50 \pm 3$ & $57 \pm 2$ & $50 \pm 2$ & $50 \pm 3$ & $59 \pm 2^{a}$ \\
\hline Entopeduncular nucleus & $44 \pm 1$ & $43 \pm 2$ & $47 \pm 4$ & $44 \pm 1$ & $44 \pm 2$ & $55 \pm 5^{a, b}$ \\
\hline Accumbens nucleus & $71+3$ & $79+4$ & $86 \pm 5^{a}$ & $70 \pm 3$ & $80 \pm 2^{a}$ & $89 \pm 5^{a}$ \\
\hline \multicolumn{7}{|l|}{ Cerebral cortex (IV layer) } \\
\hline Frontal (premotor) & $86 \pm 6$ & $85 \pm 5$ & $89 \pm 4$ & $85 \pm 5$ & $90 \pm 4^{b}$ & $95 \pm 4^{b}$ \\
\hline Prefrontal (medial) & $83 \pm 5$ & $96 \pm 5$ & $96 \pm 5$ & $83 \pm 5$ & $101 \pm 4^{a, b}$ & $97 \pm 5^{a}$ \\
\hline Parietal & $96 \pm 4$ & $92 \pm 4$ & $91 \pm 7$ & $97 \pm 4$ & $104 \pm 4^{b}$ & $113 \pm 10^{b}$ \\
\hline Sensorimotor (motor) & $89 \pm 3$ & $85 \pm 5$ & $76 \pm 6$ & $93 \pm 1$ & $90 \pm 6^{b}$ & $93 \pm 8^{\circ}$ \\
\hline (somatosensory) & $97 \pm 5$ & $89 \pm 5$ & $94 \pm 6$ & $98 \pm 5$ & $97 \pm 4^{b}$ & $111 \pm 7^{b}$ \\
\hline Visual (anterior) & $83 \pm 4$ & $80 \pm 3$ & $83 \pm 6$ & $82 \pm 3$ & $82 \pm 3$ & $90 \pm 7^{b}$ \\
\hline \multicolumn{7}{|l|}{ Cingulate } \\
\hline Anterior & $89 \pm 6$ & $85 \pm 4$ & $92 \pm 6$ & $89 \pm 5$ & $88 \pm 4$ & $96 \pm 6$ \\
\hline Posterior & $85 \pm 4$ & $87 \pm 3$ & $100 \pm 6$ & $89 \pm 5^{b}$ & $92 \pm 4^{b}$ & $104 \pm 7^{b}$ \\
\hline Pyriform & $54 \pm 3$ & $62 \pm 2^{a}$ & $67 \pm 5^{a}$ & $55 \pm 3$ & $64 \pm 3^{a}$ & $70 \pm 4^{a, b}$ \\
\hline Entorhinal & $68 \pm 3$ & $71 \pm 2$ & $69 \pm 7$ & $69 \pm 3$ & $73 \pm 2$ & $72 \pm 7$ \\
\hline
\end{tabular}

Values represent the mean \pm SEM of glucose utilization expressed in $\mu \mathrm{mol} / 100 \mathrm{gm} / \mathrm{min}$, obtained in 8 awake control rats, 7 rats injected intranigrally with $1 \mu \mathrm{M}$ muscimol, and 6 rats injected intranigrally with $1 \mathrm{mM}$ muscimol.

" Significances at $p<0.05$ level, estimated by one-way analysis of variance followed by Student's $t$-test.

${ }^{b}$ Side-to-side significant differences at the $p<0.05$ level, calculated by the paired $t$-test.

significantly different compared to the controls, these values were significantly higher compared to the ipsilateral side (Figs. $4,6,8)$.

\section{Discussion}

\section{Methodological considerations}

Control animals were subjected to intranigral injection of saline. Neither the injector track nor the saline injected in the SNR induced any significant side-to-side differences in the examined brain structures of the control group. This observation indicates that the effects elicited by intranigral muscimol injection are due to pharmacological manipulation of the nigral GABAergic system and not to any mechanical artifact.

Among the behavioral responses of rats to intranigral muscimol injection, turning of the head was observed. Because 6 rats responded to the muscimol injection with contralateral turning, 4 rats responded with ipsilateral turning, and 3 rats did not demonstrate any turning of the head, there is no indication that the consistently larger contralateral effect induced by intranigral muscimol injection is secondary to the behavioral response.

Intranigral injection of $1 \mu \mathrm{M}$ muscimol induced a significant metabolic increase in very few brain structures, whereas the injection of $1 \mathrm{~mm}$ muscimol significantly affected several ce- rebral regions. However, the metabolic values affected by the small dose were often between the control and the high dose values, indicating a biologically (although not statistically) significant dose response. Moreover, the side-to-side comparisons within each of the low and high dose groups consistently give the same lateralization of effects by both doses (Tables 1, 2, 3, 4).

\section{Effect elicited locally in the injected SNR}

Within the injected (right) $S N R$, the increased metabolic activity induced by muscimol may reflect the activation of presynaptic autoreceptors on the striatonigral GABAergic terminals. These receptors, which are sensitive to muscimol, are involved in the control of GABA release in the SN (Arbilla et al., 1979). Because electrophysiological studies have demonstrated that stimulation of the striatum inhibits neuronal firing in the SNR (Yoshida and Precht, 1971; Collingridge and Davies, 1981), the abovementioned presynaptic effect of muscimol in the SNR may induce a decrease in the tonic inhibitory action of the striatonigral GABAergic neurons and, consequently, a disinhibition of the SNR cells. Thus, it is suggested that the increased glucose consumption observed within the muscimol-injected SNR may reflect the disinhibited GABAergic reticulata efferent neurons and, even more so, their activated local collaterals, because terminals 

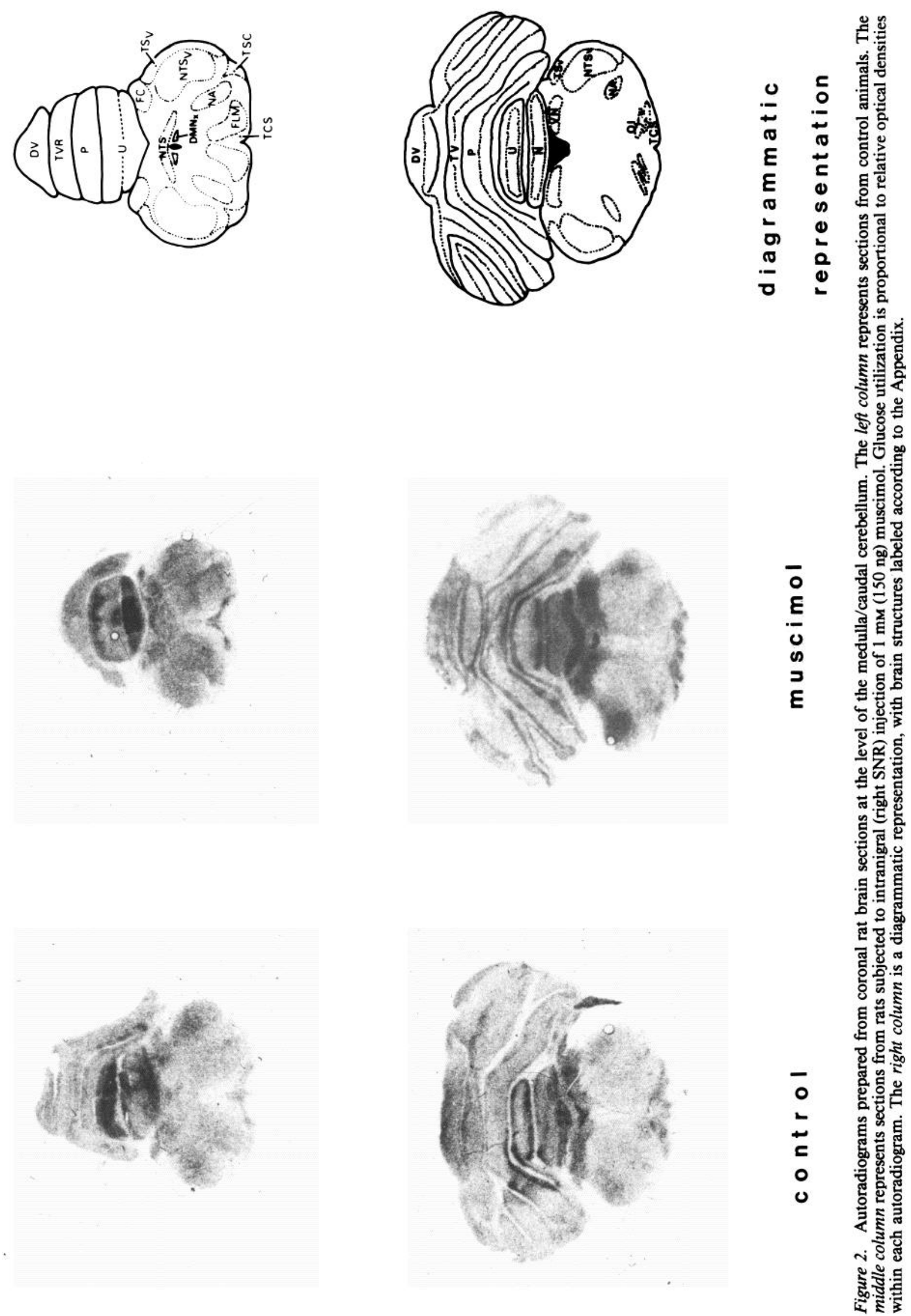

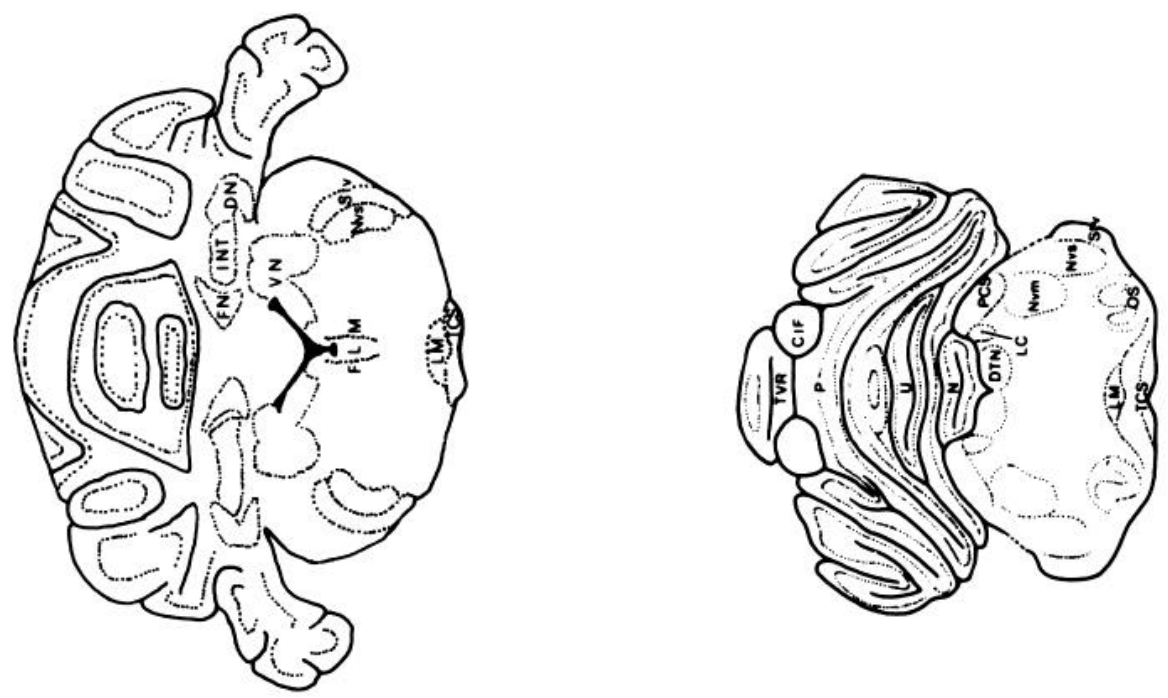

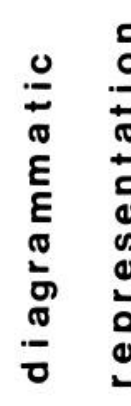
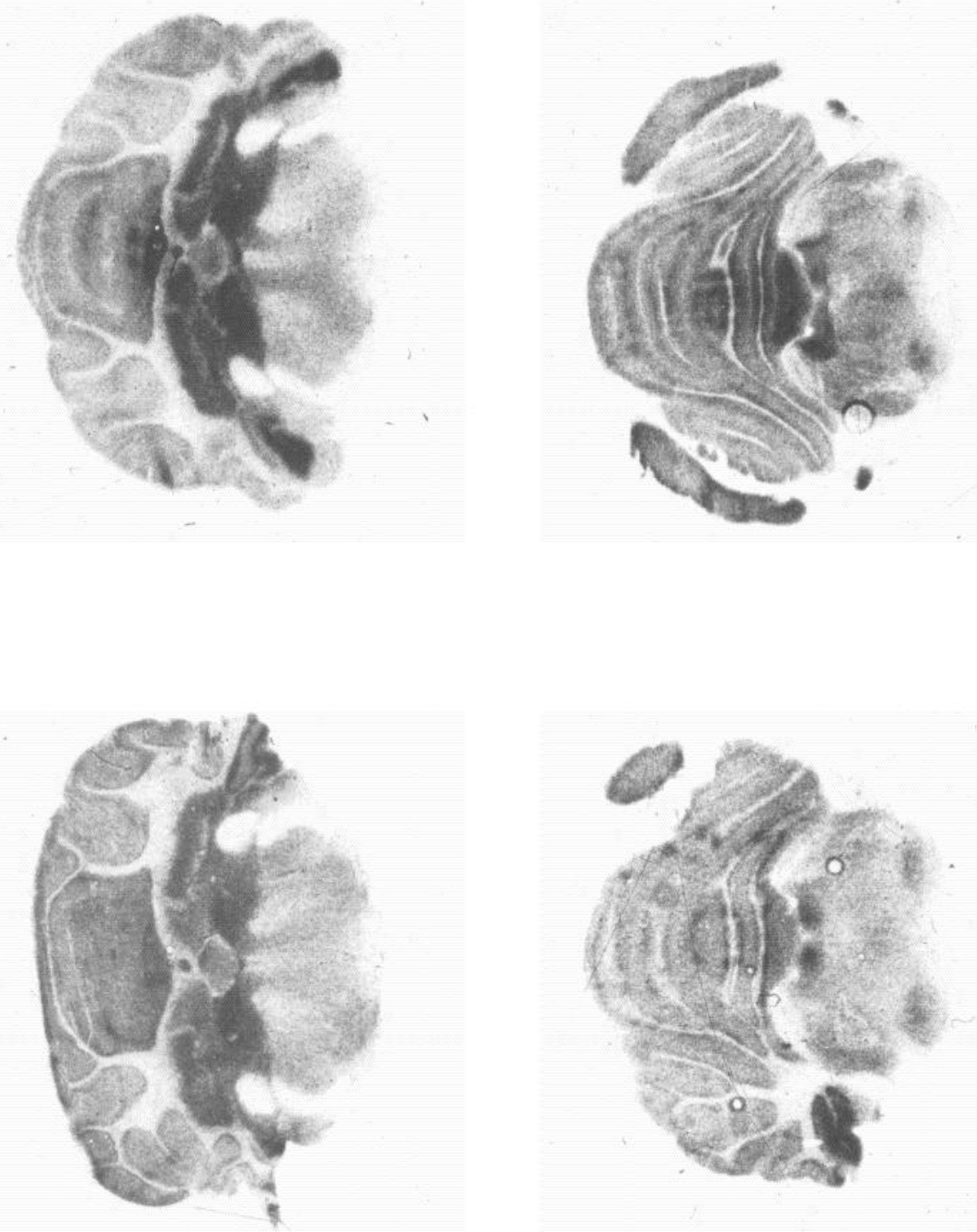

$\overline{0}$
E
0
0
J
E

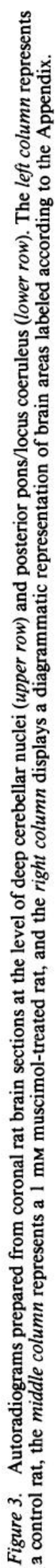


The Journal of Neuroscience, September 1990, 10(9) 2869
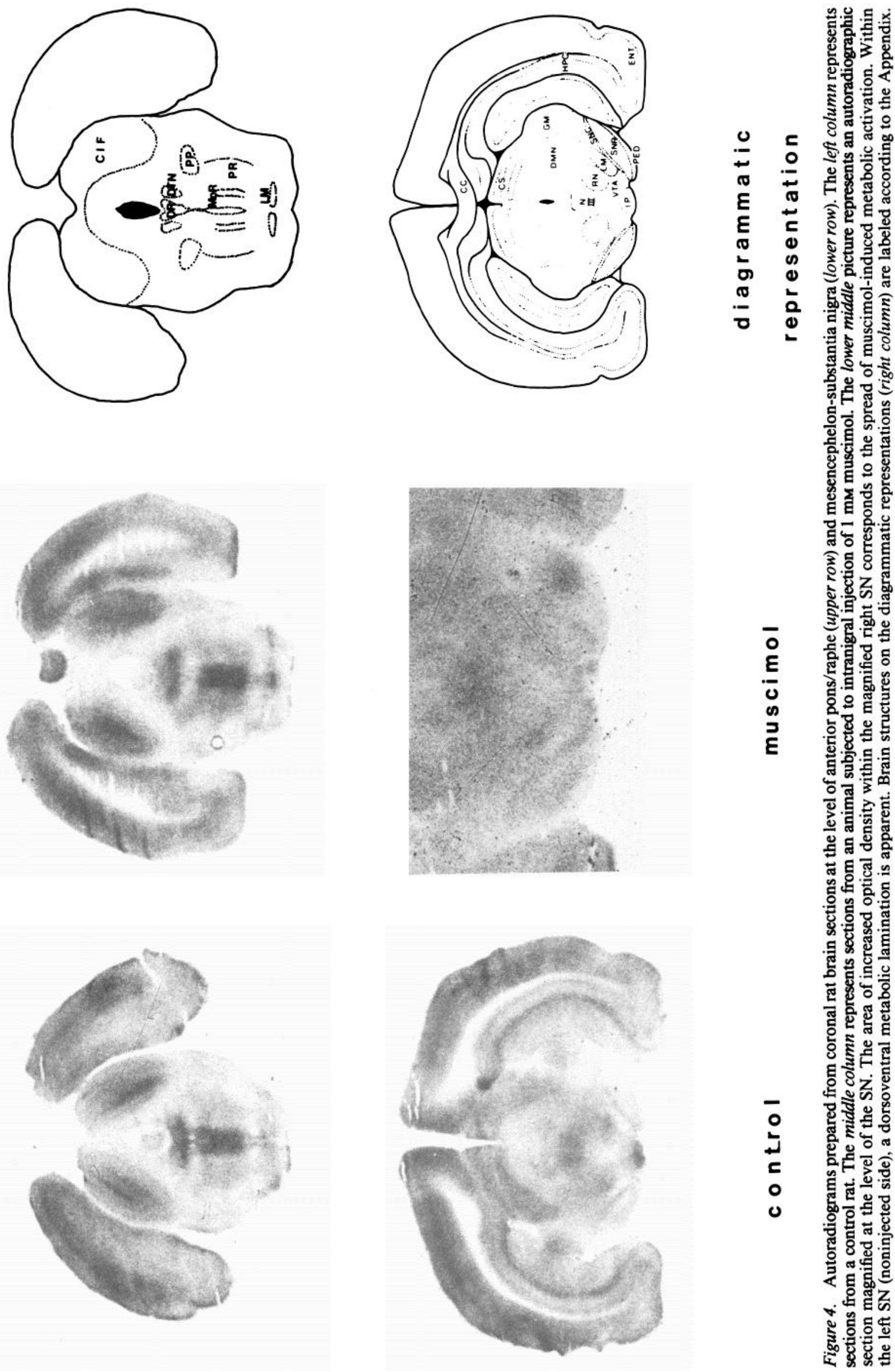

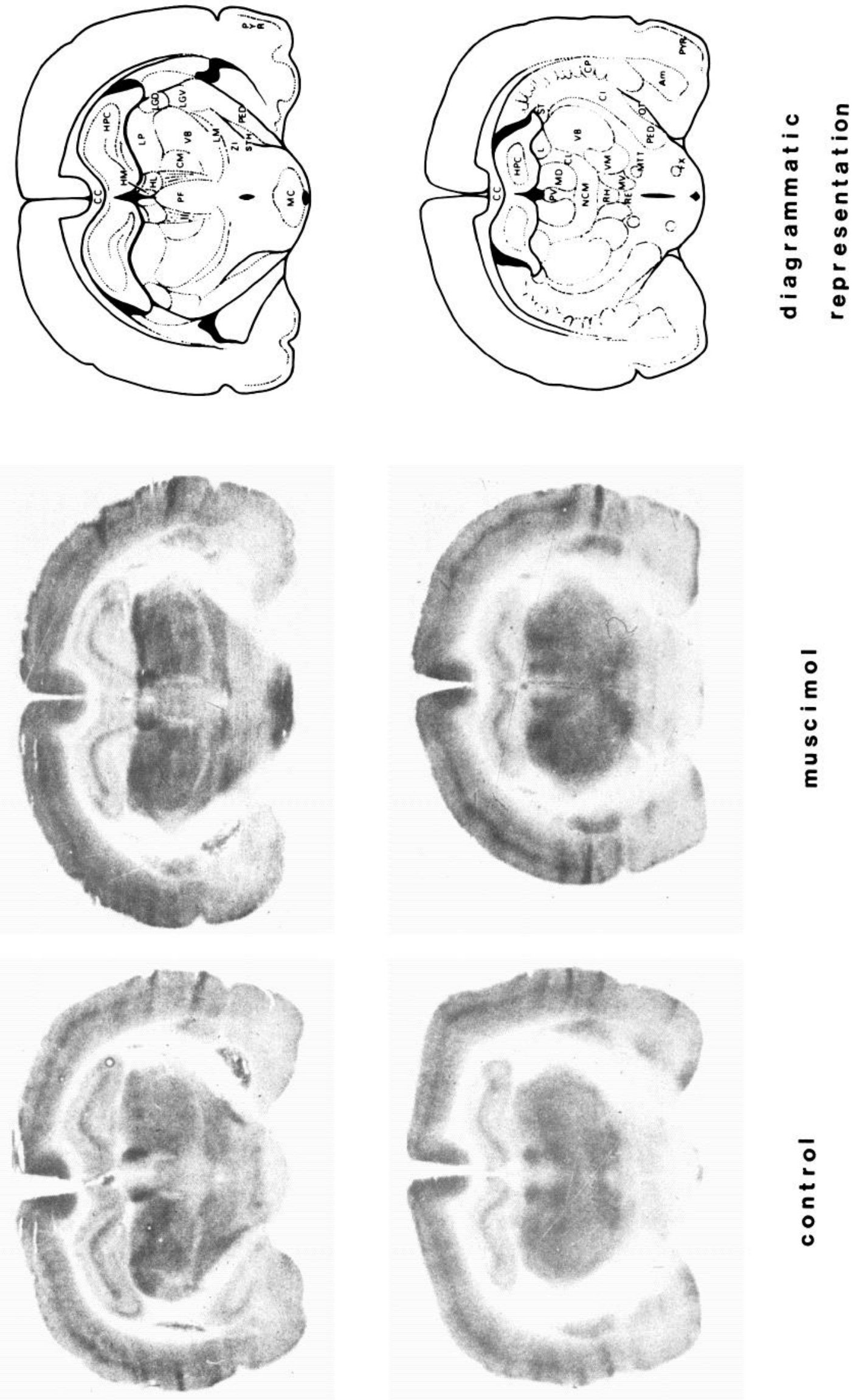

$\overline{0}$
E
0
o
ह

:

品 

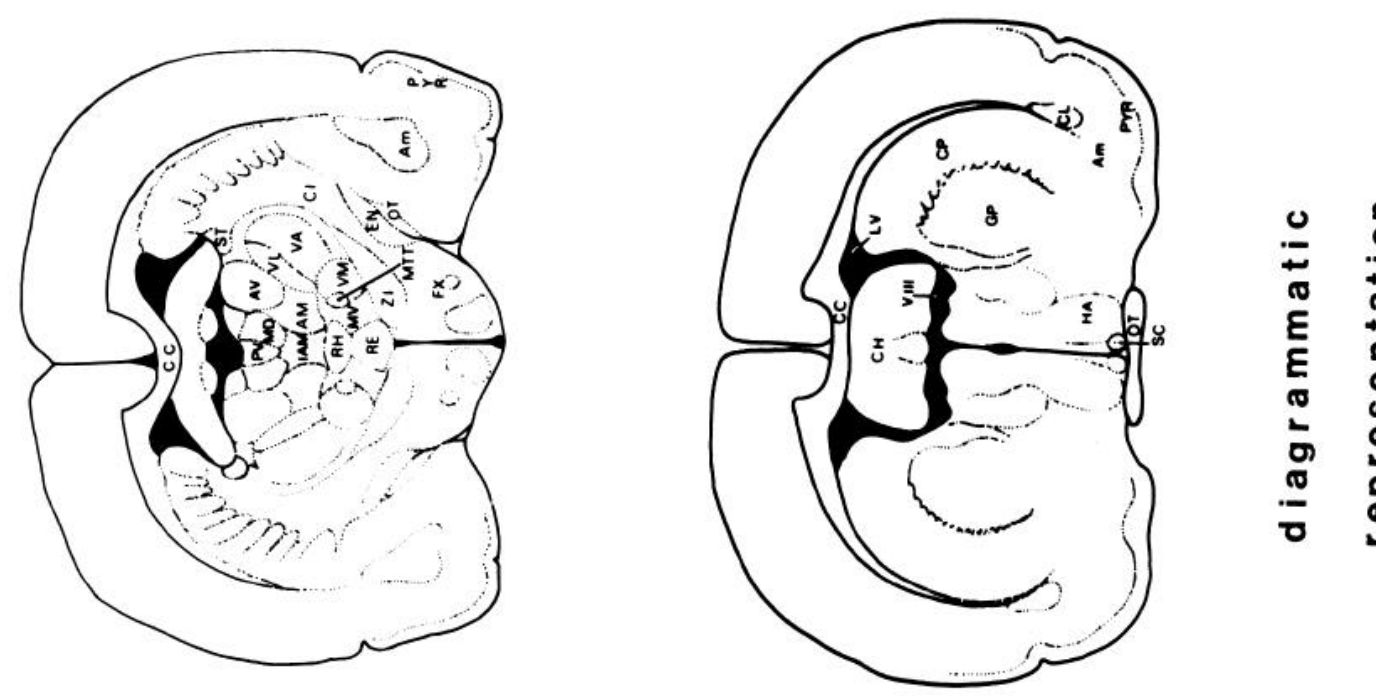

हैं

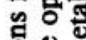

:

造
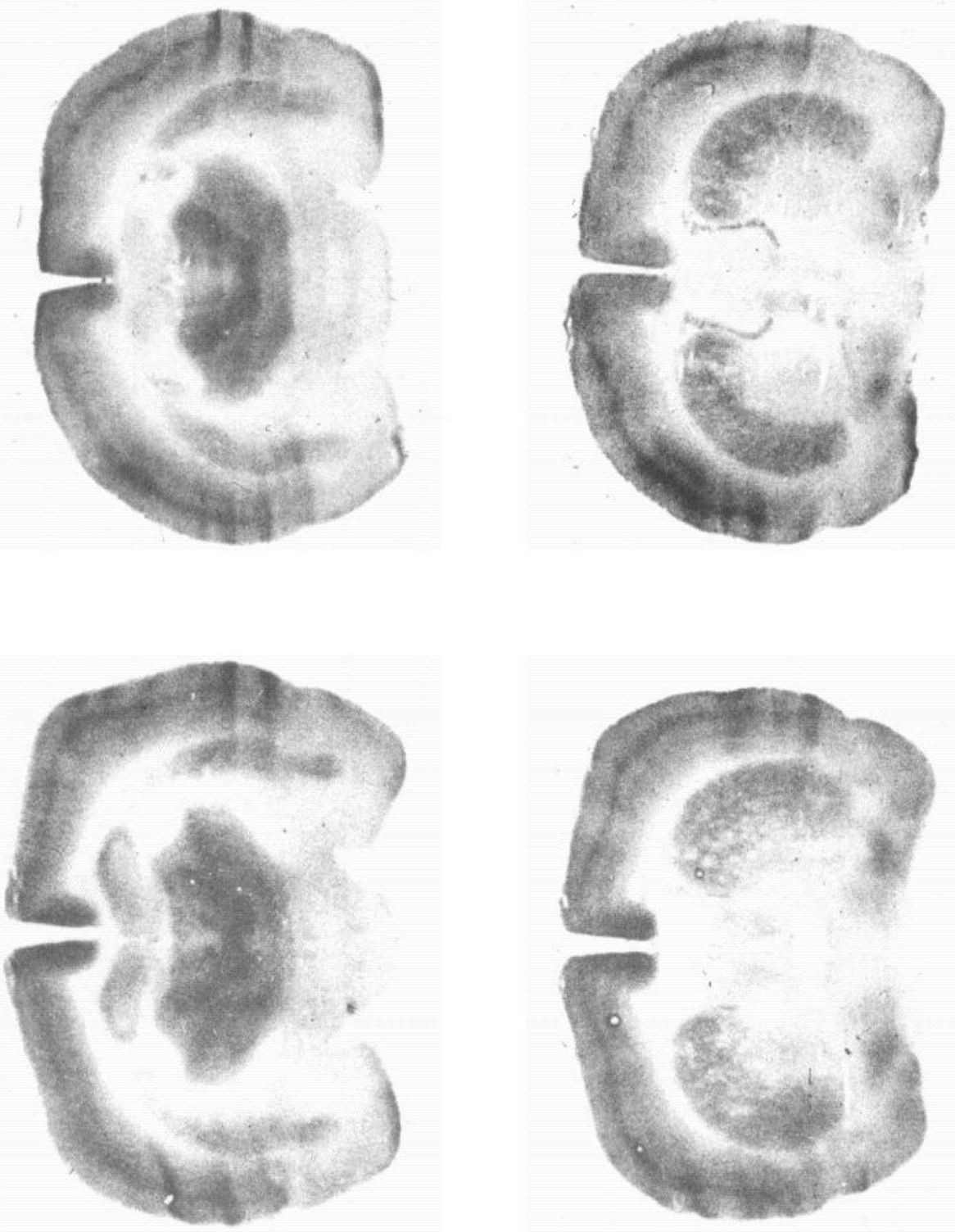

$\overline{0}$
E
0
0
$\vec{J}$
E

공

현을

ริ

융연증

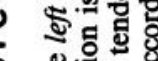

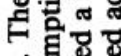

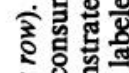

六

웜 可哭

ธี่ ส돌

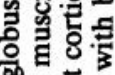

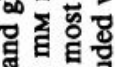

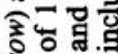

จั. 덜.

- S.

E 息密

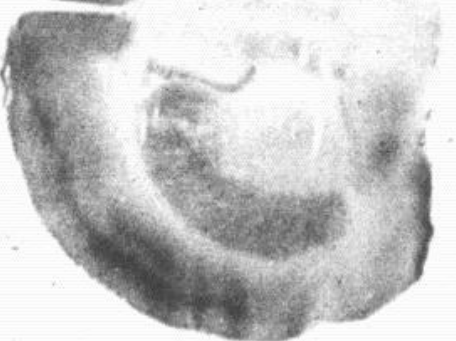

뒁.

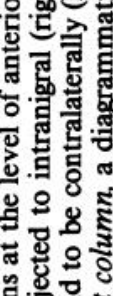

颌高弯

获 胥

동

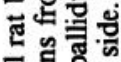

땡. 을

8 क음

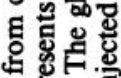

- $\quad$

은

\%

ᄃ हु일

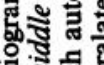

용

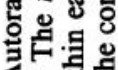

<

울를

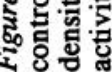



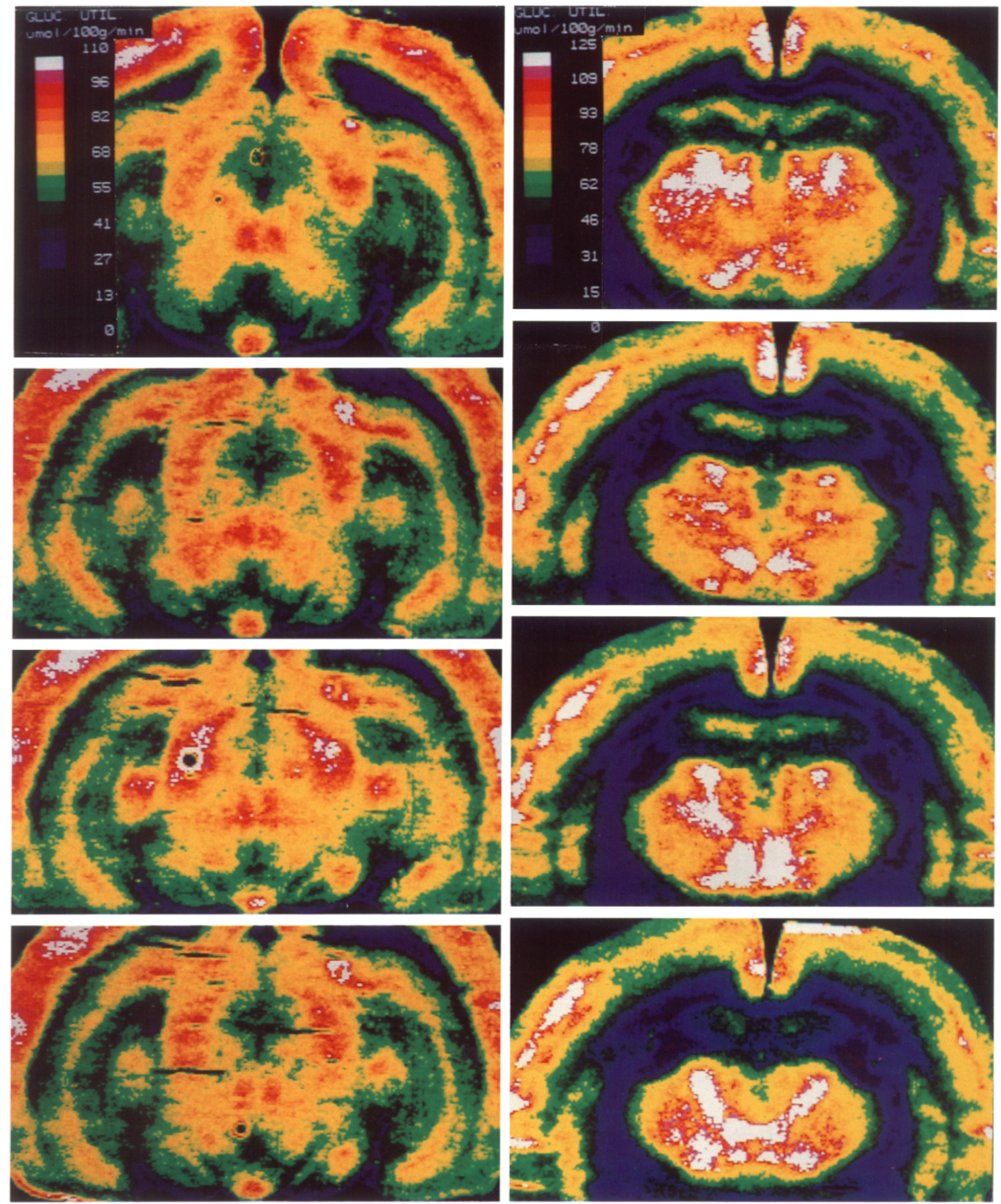

Figure 7. Computer generated, color-coded glucograms prepared from autoradiographic rat brain coronal sections at the level of the ventromedial thalamus (right column) and substantia nigra (left column). A color bar is displayed next to the sections at the top, indicating the glucose use values (in $\mu \mathrm{mol} / 100 \mathrm{gm}$ of tissue/min), which correspond to all different colors. Both columns extend from the most posterior (top) to the most anterior (bottom) thalamic and nigral levels. Right column, The increases in metabolic activity are significantly higher in the contralateral (left) ventromedial, ventrolateral, and reticularis thalamic nuclei than in the ipsilateral (to the right, muscimol-injected SNR) homologous structures. Left column, the 
appear to be more labeled than perikarya with the ${ }^{14} \mathrm{C}$-DG method (Savaki, 1989). This hypothesis is in agreement with results obtained by striatal lesions (Wooten and Collins, 1980; Hosokawa et al., 1984; Kelly and McCulloch, 1987) and by intrastriatal muscimol injection (Kelly and McCulloch, 1984), manipulations that increase nigral glucose metabolism by blocking the inhibitory striatonigral input and, consequently, by disinhibiting nigral output. Moreover, our findings support those of Kemel et al. (1983) who observed enhanced neuronal activity of the SNR cells and increased ${ }^{3} \mathrm{H}-\mathrm{GABA}$ release in the SNR (apparently from nigral local collaterals) due to reticulata cell disinhibition following intranigral superfusion with $1 \mu \mathrm{M}$ muscimol. The suggested disinhibition of SNR cells has been attributed to preferential action of muscimol at the presynaptic level.

However, the possibility that a part of the enhanced metabolic activity observed locally in the muscimol-injected SNR is due to activation of postsynaptic receptors and consequent hyperpolarization of the nigral GABAergic efferent neurons cannot be excluded at present. However, hyperpolarization should not consume much glucose, and the metabolic effects induced in projecting areas of the SNR indicate disinhibition, rather than inhibition, of reticulata cells.

It is not clear why there should be preferential action of muscimol on the presynaptic receptors (on the striatonigral terminals) and not on the postsynaptic ones (on the GABAergic nigrofugal cells). Kelly and McCulloch (1987), in their attempt to explain the inefficiency of a high dose of muscimol to act on the nigral postsynaptic receptors and, consequently, to block the SNR metabolic activation induced by striatal lesion (in other words, induced by removal of the inhibitory GABAergic striatonigral input), suggested that an alternative inhibitory transmitter may have a partial role in this pathway. The possible explanation of the striatonigrat path bcing maximally activated, so that muscimol can only disinhibit nigral cells, would be in contradiction with the neurophysiological knowledge that the striatal neurons are normally silent. However, we now know that the lesion of these silent striatal neurons induces nigral disinhibition, as well as several other consequent secondary effects. One animal recently injected intranigrally with $1.3 \mu \mathrm{l}$ of $1 \mathrm{M}$ muscimol (150 mg) demonstrated a completely different pattern of distal metabolic effects (preliminary observation in our lab), indicating a possible postsynaptic effect of muscimol in the SNR only in very high doses. Although the biological significance of applying such a high dose of muscimol intranigrally is not apparent, further studies have been undertaken in our lab, combining metabolic and recording techniques in parallel, for the deeper understanding of the pre- and postsynaptic muscimol effects in the nigra.

\section{SNR metabolic lamination}

Within the injected $\mathrm{SN}$, there was a junctional zone between the SNC and SNR that did not demonstrate metabolic activation following muscimol application (Figs. 1, 4, 7). This finding indicates either that this junctional zone is poor in GABAergic local collaterals, or that it contains cells with different receptor affinity to muscimol compared to the adjacent areas. One point of interest is that a minority of cells has been described to be located near the pars compacta, cells that are antidromically activated from the striatum and inhibited by iontophoretic application of GABA, but not DA (Guyenet and Aghajanian, 1978). Moreover, in the control SN, a dorsoventral metabolic lamination was observed (Figs. 4, 7). In the past, it has been demonstrated that the $\mathrm{SN}$ in the rat is organized in 3 dorsoventral layers, each characterized by the orientation of the local dendritic fields. The most ventral SNR layer contains dendrites oriented in parallel to the crus cerebri, the central SNR stratum has dendrites with anteroposterior orientation, and cells in the most dorsal SNR lamina are characterized by the dorsoventral extent of their dendrites (Grofova et al., 1982). Other, similar anatomical and neurophysiological evidence also exists in the literature. However, the extent to which metabolic and anatomical laminae ovelap is unknown at the present time, and the functional role of this SNR lamination is not clear. The functional speculations that different subregions of SNR are involved in specific information from the cortex through the striatum to the thalamus and superior colliculi may not hold, because all reticulata subregions contain a mixed population of projection neurons that often have branched axons (Anderson and Yoshida, 1977; Deniau et al., 1978a; Bentivoglio et al., 1979). However, the dorsoventral topographical organization of the pallidonigral (Savaki et al., 1988) and striatonigral (Domesick, 1977; Tulloch et al., 1978) projection fields, with the ventral pallidum and striatum associated with the dorsal SNR region, and with the dorsal pallidum and striatum associated with the ventral SNR, is similar to the dorsoventral metabolic lamination of SNR.

\section{Effects induced in first-order SNR-projecting areas}

The enhanced metabolic activity observed in the ipsilateral superior colliculi (SC, deep layer) is attributed to the activation of the nigrotectal projection (Beckstead et al., 1979; Chevalier et al., 1981), due to the observed disinhibition of the GABAergic reticulata cells after the intranigral muscimol action on the presynaptic autoreceptors located on the inhibitory striatonigral terminals. There is a wealth of evidence that SNR cells exert GABAergic inhibition on cells in the deep layer of the SC, a pathway that has been related to saccades (Hikosaka and Wurtz, 1989). The increased metabolic activity in the SC apparently reflects the active nigrotectal terminals rather than the inhibited SC cells, a finding consistent with other evidence that terminals are more labeled than perikarya with the ${ }^{14} \mathrm{C}-\mathrm{DG}$ method (Savaki, 1989).

The major output projection from the SNR in the rat is directed toward the VM (Clavier et al., 1976; Herkenham, 1979). The intranigral muscimol application may have activated the nigrothalamic neurons by a presynaptic action on striatonigral terminals and a consequent disinhibition of reticulata neurons. Indeed, the fact that the intranigral application of muscimol induced a metabolic activation in the ipsilateral VM similar to that observed following electrical stimulation of the SNR (Savaki et al., 1983b) indicates that our observed effect may reflect the disinhibited GABAergic nigrothalamic terminals. This hy-

activated region within the right SNR corresponds to the spread of the intranigrally injected muscimol. On the experimental autoradiograms, there was always a nigral area, corresponding to a junctional zone between the compacta and reticulata, that was not metabolically activated by any dose of muscimol (right SN). In the noninjected nigra (left SN), the dorsoventral metabolic striation can be differentiated. 

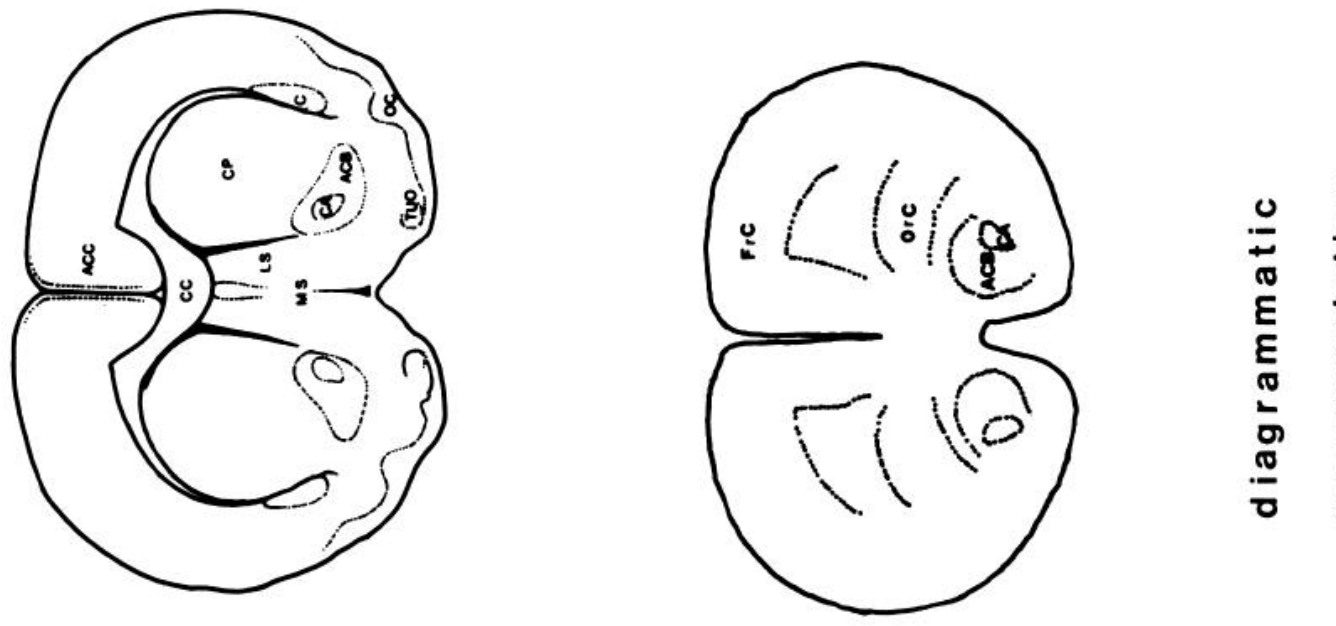

里

递

잉

5

ॠ

E $\rightleftarrows$ E

o

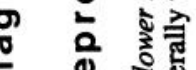
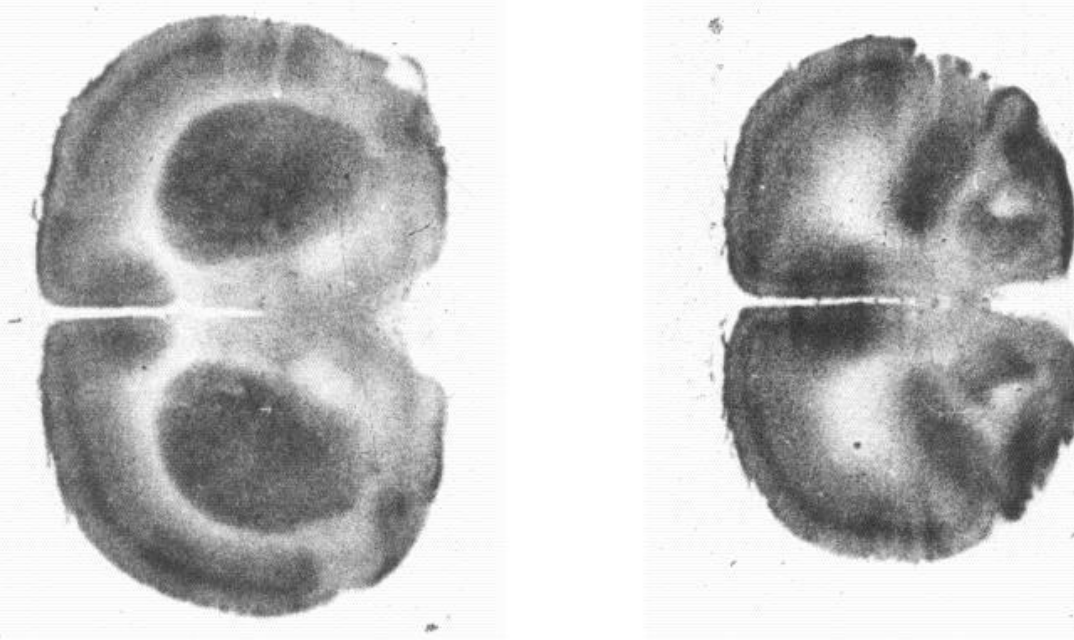

实

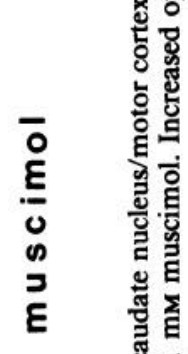
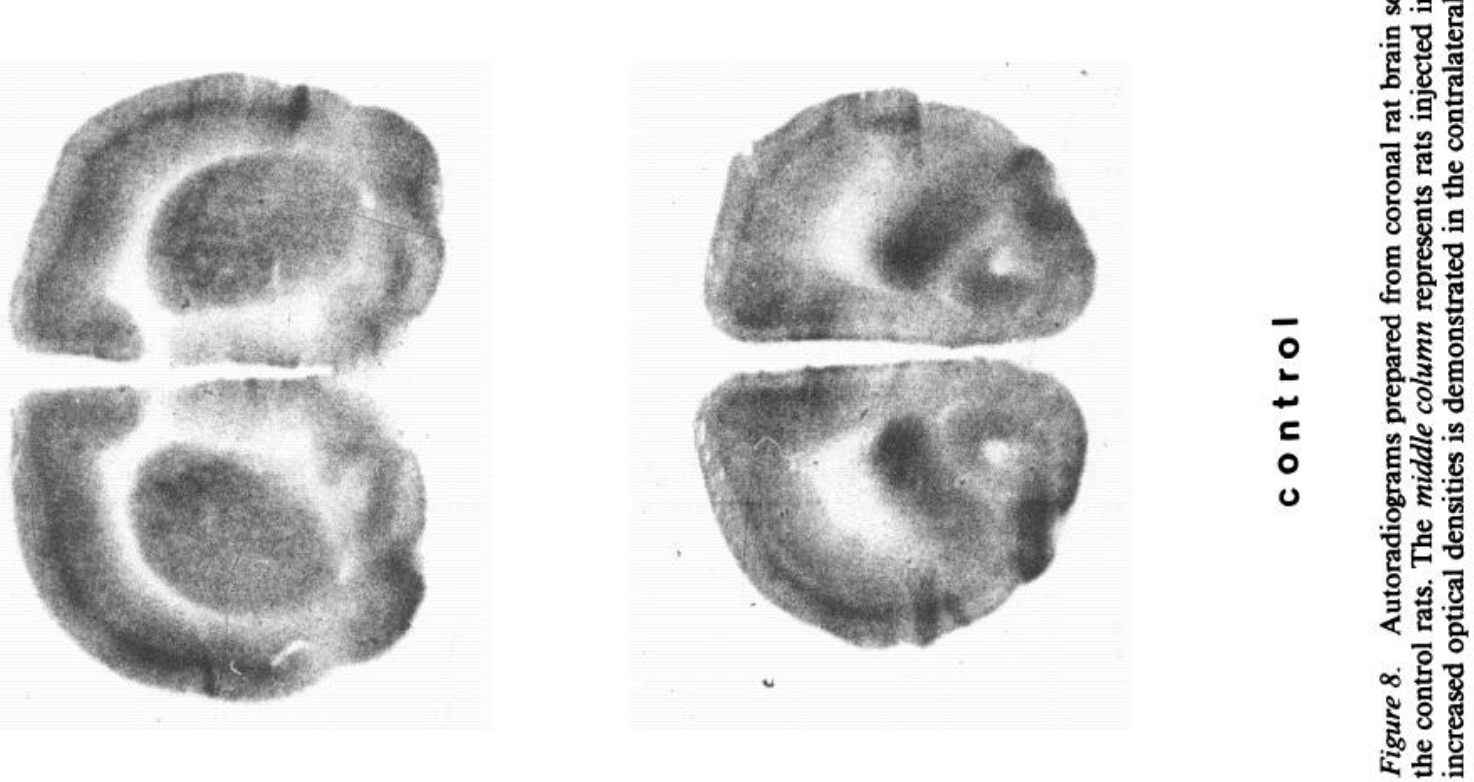
pothesis is reinforced by the observation of a simultaneous increase of ${ }^{3} \mathrm{H}-\mathrm{GABA}$ release and inhibition of global multi-unit cellular activity in the cat VM and ventrolateral (VL) and centrolateral (CL) thalamic nuclei following nigral superfusion with muscimol (Gauchy et al., 1983).

A point of interest is the finding that the contralateral VM was even more activated than the one ipsilateral to the muscimol-injected SNR. This finding, which indicates interhemispheric regulation at the thalamic level, is similar to that observed following unilateral striatal lesion, with a consequent increase in glucose use in the ipsilateral nigra, accompanied by activation in the contralateral VM (Kelly and McCulloch, 1987). This finding also resembles the intense activation of the contralateral VM following ipsilateral SNR stimulation in rats bcaring ipsilateral VM lesions (Savaki et al., 1984b). However, the SNR is not the only projecting area to the VM. The lateral habenula, cerebellar nuclei, cerebral cortex, thalamus reticularis, and SC (mostly areas contralaterally affected by intranigral muscimol injection) project converging excitatory and inhibitory afferents to the VM (Herkenham and Nauta, 1979; MacLeod and James, 1984), complicating any possible interpretation of the global metabolic effect observed locally.

\section{Effects in second-order cortical relays}

According to our hypothesis, the VM metabolic activation reflects the disinhibited nigrothalamic terminals. Because the GABAergic nigrothalamic projection is inhibitory (DiChiara et al., 1979), the VM neurons should be set silent. Furthermore, the cortical projection of the VM should be metabolically inactivated, because it has been suggested that the input from the VM to the neocortex is excitatory (Glenn et al., 1982; Girault et al., 1985).

Indeed, most of the cortical areas examined did not demonstrate metabolic activations compared to the control values, whereas the cortices ipsilateral to the injected nigra were less active than the contralateral ones. The lack of ipsilateral cortical activation observed after muscimol-induced disinhibition of the SNR cells indicates that the cortical activation observed following SNR electrical stimulation (Savaki et al., 1984b) was not due to the activation of the GABAergic nigral cell population. This cortical activation could be partly attributed to retrograde electrical stimulation of corticonigral fibers.

\section{Effects elicited in thalamic regions}

Concerning the rest of the effects observed in the thalamus (in addition to those in the VM already presented), the metabolic activations can be interpreted by some of the known anatomical connectivities. The existence of nigral inputs to the ipsilateral parafascicular, bilateral paralaminar mediodorsal, and bilateral (with sparse contralateral) VM (Gerfen et al., 1982) has been demonstrated. It has been shown that the thalamus receives inhibitory GABAergic projections from the SNR (Deniau et al., 1978b; Kilpatrick et al., 1980). Moreover, the VM sends projections to the ipsilateral reticular thalamic nucleus (Herkenham, 1979), which is reciprocally connected with the intralaminar nuclei (Scheibel and Scheibel, 1967; Jones, 1975; Nguyen-Legros et al., 1982). Finally, the intralaminar nuclei are cross-connected through the nucleus centromedian (Scheibel and Scheibel, 1967). However, the reason why the contralateral thalamic activation is more spread and intense than the ipsilateral one is not clear at present.
Based on the present findings in the thalamus following unilateral intranigral muscimol injection, we may now suggest that the transfer of information from one SNR to the contralateral hemisphere is associated with the nigrothalamic GABAergic system and is mediated via the motor, intralaminar, and reticular thalamic nuclei.

\section{Effects induced in basal ganglia components}

A point of interest is the finding that, following muscimol injection in one SNR, the contralateral SNR also demonstrated enhanced metabolic activity compared to the corresponding control value. This finding is in agreement with the increase in glucose use within the contralateral SNR following unilateral SNR electrical stimulation (Savaki et al., 1983b) and also with the increased release of ${ }^{3} \mathrm{H}-\mathrm{GABA}$ observed in the contralateral SNR following unilateral nigral superfusion with muscimol (Kemel et al., 1983). Because there is no evidence of a direct connection between the $2 \mathrm{SN}$ in the 2 hemispheres, all the above data point to the existence of 1 or more multisynaptic crossed conncctions.

The pars compacta neurons of the $\mathrm{SN}$ heavily infiltrate the SNR with extensive arborizing dendrites (Björklund and Lindvall, 1975; Juraska et al., 1977). This dendritic circuitry may be responsible for the enhanced glucose consumption observed in the ipsilateral SNC following muscimol injection into the SNR. However, the much more intense effect induced in the contralateral SNC indicates a more complex influence, particularly because the contralateral SNR was much less affected than the ipsilateral SNR.

In general, at the level of the basal ganglia components, the effects induced by unilateral SNR electrical stimulation and those induced by unilateral intranigral injection of muscimol were characterized by similar metabolic activations, with 3 exceptions. The first concerns the nucleus accumbens, which was bilaterally activated only by pharmacological manipulation. The second exception is at the level of the striatum: the fact that intranigral muscimol injection did not affect the striatal metabolism indicates that the GABAergic nigral system is not responsible for the striatal activation elicited by nigral electrical stimulation. Consequently, the striatal activation induced by SNR electrical stimulation may have been either an anterograde nigral effect mediated via the DAergic or the substance-Pergic system, or a retrograde result due to stimulation of striatonigral fibers. The third exception concerns the interhemispheric asymmetries: unilateral electrical stimulation of the SNR induced mostly bilateral effects, with the ipsilateral structures displaying the highest activations. In contrast, unilateral intranigral application of muscimol induced mainly contralateral activations within the basal ganglia components. This differential effect indicates that the ipsilateral basal ganglia activations (induced by nigral electrical stimulation) are mainly due to antidromic excitation of nigral afferents, whereas the contralateral activations are mediated via orthodromic excitation of the GABAergic SNR nerve cells. Furthermore, because unilateral VM lesion prior to ipsilateral SNR stimulation blocked the contralateral activations in the basal ganglia components (Savaki et al., 1984b), we now have enough evidence to conclude that there is a considerable transfer of information from one SNR to the contralateral basal ganglia components, mediated via the nigrothalamic GABAergic system and, thereafter, via an interthalamic polysynaptic circuitry. 


\section{Effects in the cerebellum and brainstem}

The increased metabolic activity induced in the deep cerebellar nuclei following intranigral muscimol application may be due to the SNC innervation of these nuclei (Chan Palay, 1977). A point of interest is the recent suggestion that the GABAergic nigrothalamic neurons play a gating role in cerebello-thalamocortical transmission in the VM. Consequently, the GABAergic nigral system may increase or decrease the efficacy of cerebellar afferent volleys in the VM (MacLeod and James, 1984; Bull et al., 1986).

Following intranigral application of muscimol, most of the effects induced in the medulla and pons (medullary and pontine gray, locus coeruleus, and dorsal raphe) were similar to those elicited by electrical stimulation of the SNR. The underlying interconnections (mostly reciprocal) that may interpret these metabolic activations have already been extensively discussed (Savaki et al., 1983b). The ipsilateral activation of the peribrachial pedunculopontine (PP) area, following muscimol application in the nigra, suggests that the input from the SNR to the ipsilateral PP may be GABAergic. This pontine region may partly mediate the interdependence of activity in the ipsilateral and contralateral SNR, because it projects bilaterally to the reticulata (Gerfen et al., 1982).

\section{Conclusions}

Intranigral injection of muscimol induces enhanced glucose metabolism locally, which may be due to activation of the SNR presynaptic GABAergic autoreceptors on the striatonigral terminals, with a consequent disinhibition of the nigrothalamic and nigrocollicular GABAergic neurons and their recurrent collaterals within the SNR.

Based on the metabolic alterations induced by intranigral injection of muscimol, and taking into account the metabolic effects elicited by SNR stimulation following VM lesion (Savaki et al., 1984b), we may now suggest that the nigrothalamic GABAergic system is responsible for considerable transfer of information from one SNR to the basal ganglia and associated thalamocortical components of the contralateral hemisphere.

\section{Appendix}

$\begin{array}{ll}\text { Abbreviations } \\ \text { ACB } & \text { Nucleus accumbens } \\ \text { ACC } & \text { Anterior cingulate cortex } \\ \text { AM } & \text { Anteromedial thalamic nucleus } \\ \text { Am } & \text { Amygdala } \\ \text { AV } & \text { Anteroventral thalamic nucleus } \\ \text { C } & \text { Claustrum } \\ \text { CA } & \text { Anterior commissure } \\ \text { CC } & \text { Corpus callosum } \\ \text { CH } & \text { Hippocampal commissure } \\ \text { CI } & \text { Internal capsule } \\ \text { CIF } & \text { Inferior colliculus } \\ \text { CI } & \text { Centrolateral thalamic nucleus } \\ \text { CM } & \text { Centrum-medianum thalamic nucleus } \\ \text { CP } & \text { Caudate-putamen (striatum) } \\ \text { CS } & \text { Superior colliculus } \\ \text { DMN } & \text { Deep mesencephalic nuclei } \\ \text { DMNx } & \text { Dorsal motor nucleus of the vagus } \\ \text { DN } & \text { Dentate nucleus } \\ \text { DR } & \text { Dorsal raphe } \\ \text { DTN } & \text { Dorsal tegmental nucleus } \\ \text { DV } & \text { Declive vermis } \\ \text { EN } & \text { Entopeduncular nucleus } \\ \text { ENT } & \text { Entorhinal cortex } \\ \text { EW } & \text { Edinger-Westphal nucleus } \\ & \\ & \end{array}$

\begin{tabular}{|c|c|}
\hline $\mathrm{FC}$ & Cuneate fasciculus \\
\hline FLM & Medial longitudinal fasciculus \\
\hline FN & Fastigial nucleus \\
\hline FrC & Frontal cortex \\
\hline FX & Fornix \\
\hline GLD & Lateral geniculate body, dorsal part \\
\hline GLV & Lateral geniculate body, ventral part \\
\hline GM & Medial geniculate body \\
\hline GP & Globus pallidus \\
\hline HA & Anterior hypothalamic area \\
\hline HL & Lateral habenula \\
\hline HM & Medial habenula \\
\hline $\mathrm{HPC}$ & Hippocampus \\
\hline Iam & Intraanteromedial thalamic nucleus \\
\hline Int & Interpositus nucleus \\
\hline Ip & Interpeduncular nucleus \\
\hline L & Lateral thalamic nucleus \\
\hline $\mathbf{L C}$ & Locus coeruleus \\
\hline LM & Medial lemniscus \\
\hline LP & Lateral-posterior thalamic nucleus \\
\hline LS & Lateral septum \\
\hline LV & Lateral ventricle \\
\hline $\mathrm{MC}$ & Mammillary complex \\
\hline $\mathrm{MD}$ & Mediodorsal thalamic nucleus \\
\hline MM & Medial mamillary nucleus \\
\hline MnR & Median raphe \\
\hline MS & Medial septum \\
\hline MTT & Mammillothalamic tract \\
\hline MV & Medioventral thalamic nucleus \\
\hline $\mathrm{N}$ & Nodulus (vermian lobule X) \\
\hline N III & Oculomotor nucleus \\
\hline NA & Nucleus ambiguus \\
\hline $\mathrm{NCM}$ & Nucleus centromedian \\
\hline NTS & Nucleus of the solitary tract \\
\hline NTSv & Nucleus of the spinal tract of the trigeminal nerve \\
\hline Nvm & Motor nucleus of the trigeminal nerve \\
\hline Nvs & Sensory nucleus of the trigeminal nerve \\
\hline $\mathrm{OC}$ & Olfactory cortex \\
\hline OI & Inferior olives \\
\hline OrC & Orbitofrontal cortex \\
\hline OS & Superior olivary nucleus \\
\hline OT & Optic tract \\
\hline $\mathbf{P}$ & Pyramis (vermian lobule VIII) \\
\hline PAG & Periaqueductal gray \\
\hline PCS & Superior cerebellar peduncle \\
\hline PED & Cerebral peduncle \\
\hline PF & Parafascicular thalamic nucleus \\
\hline PP & Peribrachial pedunculopontine nucleus \\
\hline PR & Pontine reticular area \\
\hline PV & Paraventricular thalamic nucleus \\
\hline PYR & Pyriform cortex \\
\hline RE & Reuniens thalamic nucleus \\
\hline RH & Rhomboid thalamic nucleus \\
\hline RN & Red nucleus \\
\hline SC & Suprachiasmatic nucleus \\
\hline $\mathbf{S N}$ & Substantia nigra \\
\hline SNC & Substantia nigra zona compacta \\
\hline SNR & Substantia nigra zona reticulata \\
\hline ST & Stria terminalis \\
\hline STH & Subthalamic nucleus \\
\hline S'Tv & Spinal trigeminal tract \\
\hline TCS & Corticospinal tract \\
\hline TSC & Spinocerebellar tract \\
\hline $\mathbf{T S}^{\mathbf{r}}$ & Spinal tract of the trigeminal nerve \\
\hline TUO & Olfactory tubercle \\
\hline TV & Tuber vermis (vermian lobule VII) \\
\hline $\mathrm{U}$ & Uvula (vermian lobule IX) \\
\hline V III & Third ventricle \\
\hline VA & Ventroanterior thalamic nucleus \\
\hline VB & Ventrobasal thalamic complex \\
\hline VL & Ventrolateral thalamic nucleus \\
\hline VM & Ventromedial thalamic nucleus \\
\hline $\mathrm{VN}$ & Vestibular nucleus \\
\hline VTA & Ventral tegmental area \\
\hline ZI & Zona incerta \\
\hline
\end{tabular}




\section{References}

Anderson M, Yoshida M (1977) Electrophysiological evidence for branching nigral projections to the thalamus and the superior colliculus. Brain Res 137:361-364.

Arbilla S, Kamal L, Langer S (1979) Presynaptic GABA autoreceptors on GABAergic nerve endings of the rat substantia nigra. Europ $J$ Pharmacol 57:211-217.

Beckstead RM, Domesick VB, Nauta WJH (1979) Efferent connections of the substantia nigra and ventral tegmental area in the rat. Brain Res 175:191-217.

Bentivoglio MD, Van der Kooy D, Kuypers HGJM (1979) The organization of the efferent projections of the substantia nigra in the rat: a retrograde fluorescence double labeling study. Brain Res 174: 1-17.

Björklund A, Lindvall O (1975) Dopamine in dendrites of substantia nigra neurons: suggestions for a role in dendritic terminals. Brain Res 85:531-537.

Bull J, Deniau JM, Chevalier G (1986) Nigral modulation of cerebellothalamo-cortical transmission in the ventral medial thalamic nucleus. Exp Brain Res 65:241-244.

Bunney BS, Aghajanian GK (1976) D-Amphetamine-induced inhibition of central dopaminergic neurons: mediation by a striato-nigral feedback pathway. Science 192:391-393.

Bunney BS, Aghajanian GK, Roth RH (1973) Comparison of effects of $\mathrm{L}$-dopa, amphetamine and apomorphine on firing rate of rat dopaminergic neurons. Nature 245:123-125.

Chan Palay V (1977) Cerebellar dentate nucleus. In: Organization, cytolopy and transmitters, pp 179-211. Berlin: Springer Vcrlag.

Chéramy A, Leviel V, Glowinski J (1981) Dendritic release of dopamine in the substantia nigra. Nature 289:537-542.

Chevalier G, Deniau JM, Thierry AM, Féger J (1981) The nigrotectal pathway: an electrophysiological reinvestigation in the rat. Brain Res 213:253-263.

Clavier RM, Atmadja S, Fibiger HC (1976) Nigrothalamic projections in the rat as demonstrated by orthograde and retrograde tracing techniques. Brain Res Bull 1:379-384.

Collingridge GL, Davies J (1981) The influence of striatal stimulation and putative neurotransmitters on identified neurons in the rat substantia nigra. Brain Res 212:345-359.

Deniau JM, Hammond C, Riszk A, Féger J (1978a) Electrophysiological properties of identified output neurons of the rat substantia nigra (pars compacta and pars reticulata): evidence for the existencc of branched neurons. Exp Brain Res 32:409-422.

Deniau JM, Lackner D, Féger J (1978b) Effects of substantia nigra stimulation on identified neurons in the VL-VM thalamic complex: comparison between intact and chronically decorticated cats. Brain Res 145:27-35.

Dermon CR, Tzagournissakis M, Pizarro P, Savaki HE (1989) Specific bilateral alterations in local cerebral glucose utilization following intranigral injection of muscimol and substance P. Neuroscience Abstract 15:911.

DiChiara G, Porceddu ML, Morelli M, Mulas ML, Gessa GL (1979) Evidence for a GABAergic projection from the substantia nigra to the ventromedial thalamus and to the superior colliculus of the rat. Brain Res 176:273-284.

Dumesick VB (1977) The topographic organization of the striatonigral connection in the rat. Anat Res 187:567.

Gauchy G, Kemel ML, Glowinski J, Besson MJ (1980) In vivo release of endogenously synthesized ${ }^{3} \mathrm{H}-\mathrm{GABA}$ from the cat substantia nigra and the pallido entopeduncular nuclei. Brain Res 193:129-141.

Gauchy C, Kemel ML, Romo R, Chéramy A, Glowinski J, Besson MJ (1983) Effects of nigral application of muscimol on release of ${ }^{3} \mathrm{H}-\gamma$ amino butyrate and on multi-unit activity in various cat thalamic nuclei. Neuroscience 10:781-788.

Gerfen CR, Staines WA, Arbuthnott GW, Fibiger HC (1982) Crossed connections of the substantia nigra in the rat. J Comp Neurol 207: 283-303.

Girault JA, Savaki HE, Desban M, Glowinski J, Besson MJ (1985) Bilateral cerebral metabolic alterations following lesion of the ventromedial thalamic nucleus: mapping by the ${ }^{14} \mathrm{C}$-deoxyglucose method in conscious rats. $\mathbf{J}$ Comp Neurol 231:137-149.

Glenn LL, Hada J, Roy JP, Deschenes M, Steriade M (1982) Anterograde tracer and field potential analysis of the thalamus in cat. Neuroscience $7: 1861-1877$.
Grofova I, Deniau JM, Kitai ST (1982) Morphology of the substantia nigra pars reticulata projection neurons intracellularly labeled with HRP. J Comp Neurol 208:352-368.

Guyenet PG, Aghajanian GK (1978) Antidromic identification of dopaminergic and other output neurons of the rat substantia nigra. Brain Res 150:69-84.

Herkenham M (1979) The afferent and efferent connections of the ventromedial thalamic nucleus in the rat. J Comp Neurol 183:487518.

Herkenham M, Nauta WJ (1979) Efferent connections of the habenular nuclei in the rat. J Comp Neurol 187:19-48.

Hikosaka O, Wurt7. RH (1989) The basal ganglia in the neurobiology of saccadic eye movements (Wertz RH, Goldberg M, eds), pp 257275. Amsterdam: Elsevier Science Publishers BV (Biomedial Division).

Hosokawa S, Motohiro K, Shima F, Tobimatsu S, Kuroiwa Y (1984) Local cerebral glucose utilization altered in rats with unilateral electrolytic striatal lesions and modification by apomorphine. Brain Res 324:59-68.

Jones EG (1975) Some aspects of the organization of the thalamic reticular complex. J Comp Neurol 162:285-308.

Juraska JM, Wilson CJ, Groves PM (1977) The substantia nigra in the rat: a Golgi study. J Comp Neurol 172:585-600.

Kelly PA, McCulloch J (1984) Extrastriatal circuits activated by intrastriatal muscimol: a ${ }^{14} \mathrm{C}$-2-deoxyglucose investigation. Brain Res 292:357-366.

Kelly PAT, McCulloch J (1987) Cerebral glucose utilization following striatal lesions: the effects of the GABA against muscimol and the dopaminergic agonist apomorphine. Brain Res 425:290-300.

Kemel ML, Gauchy C, Romo R, Glowinski J, Besson MJ (1983) In vivo release of ${ }^{3} \mathrm{H}-\mathrm{GABA}$ in cat caudate nucleus and substantia nigra. I. Bilateral changes induced by a unilateral nigral application of muscimol. Brain Res 272:331-340.

Kilpatrick IC, Starr MS, Fletcher A, James TA, MacLeod NK (1980) Evidence for a GABAergic nigrothalamic pathway in the rat. I. Behavioral and biochemical studies. Exp Brain Res 40:45-54.

Leviel V, Chéramy A, Nieoullon A, Glowinski J (1979) Symmetrical bilateral changes in dopamine release from the caudate nuclei of the cat induced by unilateral nigral application of glycine and GABArelated compounds. Brain Res 175:259-270.

Lidsky TI, Manetto C, Schneider JS (1985) A consideration to sensory factors involved in motor functions of the basal ganglia. Brain Res Rcv 9:133-146.

MacLeod NK, James TA (1984) Regulation of cerebello-cortical transmission in the rat ventromedial thalamic nucleus. Exp Brain Res 55: 535-552.

McCulloch J, Savaki HE, McCulloch MC, Sokoloff L (1979) Specific distribution of metabolic alterations in cerebral cortex following apomorphine administration. Nature 282:303-305.

Nguyen-Legros J, Cesaro P, Pollin B, Laplante S, Gay M (1982) Thalamostriatal neurons with collateral projection onto the rostral reticular thalamic nucleus: anatomical study in the rat by retrograde axonal transport of irox-dextran and horseradish peroxidase. Brain Res 249: 147-152.

Paxinos G, Watson C (1982) The rat brain in stereotaxic coordinates. Sydney: Academic Press.

Savaki HE (1989) The role of thalamic relays in the basal ganglia interhemispheric relations, as demonstrated by the autoradiographic ${ }^{14} \mathrm{C}$-deoxyglucose method. In: Brain imaging techniques and applications (Sharif NA, Lewis ME, eds), pp 262-279. Chichester: Ellis Horwood Limited.

Savaki HE, Desban M, Glowinski J, Besson MJ (1983a) Local cerebral glucose consumption in the rat. I: Effects of halothane anaesthesia. J Comp Neurol 213:36-45.

Savaki HE, Desban M, Glowinski J, Besson MJ (1983b) Local cerebral glucose consumption in the rat. II: Effects of unilateral substantia nigra stimulation in conscious and halothane anaesthetized animals. J Comp Neurol 213:46-65.

Savaki HE, Girault JA, Desban M, Glowinski J, Besson MJ (1984a) Adaptive reaction of nigral neurons following lesions of their ventromedial-thalamic projection field. Brain Res 302:190-195.

Savaki HE, Girault JA, Desban M, Glowinski J, Besson MJ (1984b) Local cerebral metabolic effects induced by nigral stimulation following ventromedial thalamic lesions. II: Sensory-motor, reticular and structures. Brain Res Bull 12:609-617. 
Savaki HE, Girault JA, Desban M, Glowinski J, Besson MJ (1985) Local cerebral metabolic effects induced by nigral stimulation following ventromedial thelamic lesions. II: Sensory-motor, reticular and limbic systems. Brain Res Bull 14:287-296.

Savaki HE, Pizarro $P$, Dermon C, Arsenis S (1988) Deoxyglucose analysis of the specific topographic functional interrelations between substantia nigra and globus pallidus. Brain Res Bull 21:855-863.

Scheibel ME, Scheibel AB (1967) Structural organization of nonspecific thalamic nuclei and their projections toward cortex. Brain Res 6:60-94.

Sokoloff L, Reivich M, Kennedy C, DesRosiers MH, Patlak CS, Pettigrew DK, Sakurada O, Shinohara M (1977) The ${ }^{14} \mathrm{C}$-deoxyglucose utilization: theory, procedure and normal values in the conscious and anesthetized rat. J Neurochem 28:897-916.

Starr MS, Summerhayes M, Kilpatrick IC (1983) Interactions between dopamine and $\gamma$-aminobutyrate in the substantia nigra: implications for the striatonigral output hypothesis. Neuroscience 8:547-559.
Tulloch IF, Arbuthnott GW, Wright AK (1978) Topographical organization of the striatonigral pathway revealed by anterograde and retrograde neuroanatomical tracing techniques. J Anat 127:425-441.

Waszczak BL, Eng N, Walters JR (1980) Effect of muscimol and picrotoxin on single unit activity of substantia nigra neurons. Brain Res 188:185-197.

Wechsler LR, Savaki HE, Sokoloff L (1979) Effects of d- and L-amphetamine on local cerebral glucose utilisation in the conscious rat. J Neurochem 39:15-22.

Wooten GF, Collins RC (1980) Regional brain glucose utilization following intrastriatal injections of kainic acid. Brain Res 201:173184.

Yoshida M, Precht W (1971) Monosynaptic inhibition of neurons of the substantia nigra by caudato-nigral fibers. Brain Res 32:225-228. 